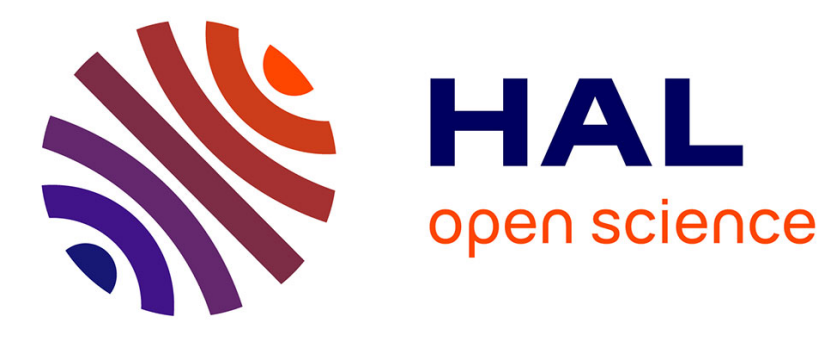

\title{
Tunneling in Squeezing Ground: Effect of the Excavation Method
}

Manuel de La Fuente, Jean Sulem, Reza Taherzadeh, Didier Subrin

\section{To cite this version:}

Manuel de La Fuente, Jean Sulem, Reza Taherzadeh, Didier Subrin. Tunneling in Squeezing Ground: Effect of the Excavation Method. Rock Mechanics and Rock Engineering, 2020, 53 (2), pp.601-623. 10.1007/s00603-019-01931-4 . hal-03119942

\section{HAL Id: hal-03119942 https://hal.science/hal-03119942}

Submitted on 25 Jan 2021

HAL is a multi-disciplinary open access archive for the deposit and dissemination of scientific research documents, whether they are published or not. The documents may come from teaching and research institutions in France or abroad, or from public or private research centers.
L'archive ouverte pluridisciplinaire HAL, est destinée au dépôt et à la diffusion de documents scientifiques de niveau recherche, publiés ou non, émanant des établissements d'enseignement et de recherche français ou étrangers, des laboratoires publics ou privés. 


\title{
Tunneling in squeezing ground: effect of the excavation method
}

\author{
Manuel DE LA FUENTE ${ }^{1,2}$, \\ Jean SULEM ${ }^{2}$, \\ Reza TAHERZADEH ${ }^{1}$, \\ Didier SUBRIN ${ }^{3}$ \\ ${ }^{1}$ Tractebel Engie, 5 Rue du 19 Mars 1962, 92622 Gennevilliers, France \\ ${ }^{2}$ Laboratoire Navier/CERMES, Ecole des Ponts ParisTech, IFSTTAR, CNRS, Université \\ Paris-Est, 6, 8 Avenue Blaise Pascal, 77455 Marne la Vallée, France, Email: \\ jean.sulem@enpc.fr, Phone : +33164153545 \\ ${ }^{3}$ Centre d'Etudes des Tunnels (CETU), 25 Avenue François Mitterrand, 69674 Bron Cedex 1, \\ France
}

\begin{abstract}
:
Tunnel excavation in squeezing ground exhibits large time-dependent and often anisotropic deformation. Within the context of the Fréjus road tunnel and its safety gallery excavated under the Alps between France and Italy, an interesting configuration of two parallel tunnels under squeezing ground conditions is observed. The special feature of this case study lies in the fact that both tunnels have been excavated in similar geotechnical conditions but with different excavation techniques. The road tunnel was excavated with conventional drill and blast methods in the seventies whereas the safety gallery was excavated between 2009 and 2016 with a single shield Tunnel Boring Machine (TBM).

The present paper presents monitoring data processing and numerical simulations of both tunnels with the aim of studying the influence of the excavation method on the timedependent tunnel response. A calibration of a visco-elasto-plastic anisotropic constitutive model based on the back-analysis of convergence measurements retrieved during the excavation of the Fréjus road tunnel is carried out. The identified ground behavior can be extrapolated to the parallel zones of the safety gallery. In particular, we are interested in the prediction of the stress state in the segmental lining of the gallery during its excavation and the comparison with in situ measurements. It is shown that the time-dependent behavior of the ground is affected by the excavation technique. Finally, an attempt to predict the long-term response of both tunnels is proposed.
\end{abstract}

Keywords: Squeezing ground; Conventional drill and blast tunnel excavation; Tunnel Boring Machine; The Fréjus road tunnel; The Fréjus safety gallery 


\section{List of symbols}

2

$C_{\infty x} \quad$ Instantaneous convergence obtained in the case of an infinite rate of face advance (no time-dependent effect)

$X \quad$ Parameter related to the distance of influence of the tunnel face

$T \quad$ Parameter related to time-dependent behavior of the system (rock mass formation-support)

$m \quad$ Parameter which represents the relationship between the long-term total convergence and the instantaneous convergence

$n \quad$ Form-factor of the fitting law which is often taken equal to 0.3

$\beta \quad$ Anisotropy ratio of the convergence data

$\xi \quad$ Variability index of the convergence data

$E \quad$ Young's modulus of the solid matrix

$v \quad$ Poisson's ratio of the solid matrix

$K \quad$ Elastic bulk modulus of the solid matrix

$G_{K} \quad$ Kelvin shear modulus of the solid matrix

$\eta_{K} \quad$ Kelvin dynamic viscosity of the solid matrix

$G_{M} \quad$ Elastic shear modulus of the solid matrix

$\eta_{M} \quad$ Maxwell dynamic viscosity of the solid matrix

$c \quad$ Cohesion of the solid matrix

$\phi \quad$ Friction angle of the solid matrix

$\psi \quad$ Dilation angle of the solid matrix

$\sigma_{t} \quad$ Tension limit of the solid matrix

$c_{j} \quad$ Cohesion of the weak planes

$\phi_{j} \quad$ Friction angle of the weak planes

$\psi_{j} \quad$ Dilation angle of the weak planes

$\sigma_{t j} \quad$ Tension limit of the weak planes

$\alpha \quad$ Variability index of the constitutive parameters (describing the damage degree of the rock mass) 


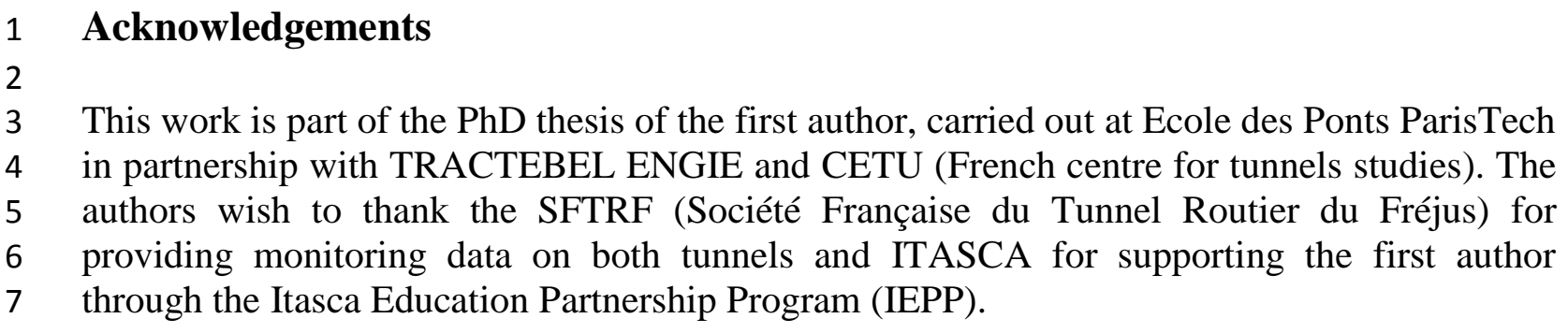

This work is part of the PhD thesis of the first author, carried out at Ecole des Ponts ParisTech in partnership with TRACTEBEL ENGIE and CETU (French centre for tunnels studies). The authors wish to thank the SFTRF (Société Française du Tunnel Routier du Fréjus) for providing monitoring data on both tunnels and ITASCA for supporting the first author 


\section{Introduction}

When dealing with squeezing ground conditions, the technique of excavation has a huge influence on the tunnel response. The excavation can be adjusted to the encountered ground conditions when it is executed with conventional techniques: an active or a passive approach can be adopted. As described in Barla (2001), the active approach refers to the so-called 'heavy method' which consists in preventing rock deformation by the installation of a sufficiently strong support/stabilization/lining system, whereas the passive approach refers to the so-called 'yielding support method' which aims at accommodating the large deformations. On the other hand, when the tunnel is excavated with a Tunnel Boring Machine (TBM), the adaptation and the optimization of the design to the encountered ground conditions are difficult to achieve as the tunnel geometry and support system are imposed by the TBM characteristics. Large convergence of the ground can lead to sticking of the cutter head, jamming of the TBM and overloading of the segmental lining. The immediate installation of the lining prevents a direct study of the ground response through convergence measurements. Information can be retrieved through the monitoring of the thrust force which has to overcome the friction exerted by the ground over the TBM shield to avoid entrapment (e.g. Ramoni \& Anagnostou, 2006, 2008, 2010). Monitoring of strains and stresses in the segmental lining can provide an accurate information on the time-dependent interaction between the ground and the support.

An interesting question concerns the effect of the excavation method on the ground behavior. Drill and blast methods can significantly damage the rock mass whereas TBM excavation reduces the disturbance of the ground. Therefore, the long term ground behavior might be affected by the excavation method. It has also been observed in several well documented cases that, when the water amount in the ground is important, the deformations observed during the construction of a second parallel tube are smaller than in the first tube although the geology and the construction method of the second tube were the same as in the first tube like for example in the Simplon tunnel (Steiner 1996). This was attributed to the drainage and consolidation effects triggered by the excavation of the first tube. Even when the two tubes are far enough to preclude any mutual interaction, different responses can be observed in relation with the strong heterogeneity and local variability of the properties in squeezing grounds (Mezger et al., 2013).

The Fréjus road tunnel and its safety gallery are two examples of tunnels excavated in squeezing ground. The Fréjus road tunnel was excavated by conventional drill and blast methods in the seventies linking France and Italy under the Alps. The design and construction of the tunnel were on behalf of a two-state company named Société française du tunnel routier du Fréjus (SFTRF) for the French part and Società italiana per il Traforo Autostradale del Frejus (SITAF) for the Italian part. Since the fire which took place in Montblanc tunnel in 1999, a new safety legislation for tunnels was established. In order to be in accordance with it, the SFTRF and the SITAF decided to excavate a safety gallery between 2009 and 2016 which runs parallel to the existing road tunnel at a $50 \mathrm{~m}$ average distance between the axes of both tunnels. The safety gallery was excavated with a Tunnel Boring Machine (TBM). 
For the Fréjus road tunnel, the ground response can be studied by analyzing convergence data retrieved during the excavation. Convergences were monitored over a period of four months until the installation of the final lining. By analyzing convergence data retrieved from the road tunnel a good understanding of the face advance effects and of the time-dependent behavior of the ground is reached (De la Fuente et al., 2017). The present paper aims at studying the effect of the excavation method on the time-dependent response of the tunnel. It is carried out by calibrating a visco-elasto-plastic anisotropic constitutive model on the convergence data recorded in the road tunnel during its excavation. This constitutive model is then used to describe the behavior of the neighboring zones of the safety gallery in order to compute its time-dependent response. Finally, a numerical prediction of the long-term response of both tunnels is also carried out.

\section{Case study: The Fréjus road tunnel and its safety gallery}

\subsection{General context of the Fréjus road tunnel and of its safety gallery}

The Fréjus road tunnel came into service on July, 12th 1980. A new path between North-West Europe and the Mediterranean was opened. The tunnel links Modane (France) and Bardonnechia (Italy) under the ridge between the pic of Fréjus $(3019 \mathrm{~m})$ and the pic of GrandVallon in the Alps, following an average North-South direction. The geological and geotechnical context is described in the papers of Beau et al. (1980) and Lévy et al. (1981) (see also Sulem (2013)).

The tunnel is $12.87 \mathrm{~km}$ long and $11.6 \mathrm{~m}$ wide between the sidewalls with a two-lane horse shoe section. The overburden along most of the layout is over $1000 \mathrm{~m}$ (with a maximum of $1800 \mathrm{~m}$ ). The Italian tunnel portal is at an altitude of $1297 \mathrm{~m}$ whereas the French tunnel portal is at an altitude of $1228 \mathrm{~m}$. The tunnel slopes down $0.54 \%$ from Italy towards France. Two ventilation shafts have been placed at $1 / 3$ and $2 / 3$ of the tunnel length together with six ventilation plants.

The safety gallery is $9.5 \mathrm{~m}$ wide and $13 \mathrm{~km}$ long. As for the road tunnel, the safety gallery slopes down $0.54 \%$ from France towards Italy and the average overburden is of $1000 \mathrm{~m}$ (with a maximum of $1800 \mathrm{~m}$ ). The safety gallery is connected with the road tunnel by means of 34 inter-tubes spaced of $400 \mathrm{~m}$. Among them, 5 by-pass, large enough to allow the circulation of emergency vehicles between the road tunnel and the safety gallery, have been installed. Ten technical stations as well as two ventilation plants were also built.

Both tunnels mainly go through a calcareous schist formation, however tunnels entrances are constituted of a sequence of various grounds (anhydrite, black and green schist, cargneule) (Fig1.).

\section{Fig1. Geological profile of the alignment}

The dip direction of the schistosity planes $\left(\mathrm{N} 270^{\circ}-\mathrm{N} 315^{\circ}\right)$ is approximately parallel to the longitudinal axis of both tunnels and its dip angle varies between $25^{\circ}$ and $50^{\circ}$. The calcschist result from a light metamorphism of marls and limy marls with the formation of phyllitous minerals (muscovite, chlorite). As noted by Panet, (1996), some variations are observed with 
zones which are more calcareous and zones which are more micaceous with some graphitic beds. As mentioned later in the analysis of the convergence data, the mineralogy has been recognized to have a significant influence on the magnitude of the convergence of the tunnel walls. These minerals favor the formation of schistosity planes during the metamorphism of the rock. When the schistosity planes are well formed and are favorably oriented, buckling phenomenon can be triggered during the excavation of the tunnel. The anisotropy of the calcschists formation is clearly highlighted by the seismic data. The wave velocity in the direction of the plane of schistosity varies between $4000 \mathrm{~m} / \mathrm{s}$ and $6000 \mathrm{~m} / \mathrm{s}$ whereas it varies between $1300 \mathrm{~m} / \mathrm{s}$ and $3000 \mathrm{~m} / \mathrm{s}$ in the direction perpendicular to it. The influence of the anisotropy of the structure has also been studied by mechanical tests (Beau et al. 1980). In spite of the strong heterogeneity of the ground, measurements of the Young's modulus carried out in the parallel direction to the schistosity planes (between $25 \mathrm{GPa}$ and $60 \mathrm{GPa}$ ) are slightly higher than measurements carried out in the perpendicular direction to the schistosity planes (between $10 \mathrm{GPa}$ and $55 \mathrm{GPa}$ ). The uniaxial compression strength (UCS) measured in the perpendicular direction to the schistosity planes (87\% of the UCS measurements vary between $30 \mathrm{MPa}$ and $100 \mathrm{MPa}$ ) is higher than the UCS measured in the parallel direction to the schistosity planes ( $80 \%$ of the UCS measurements vary between $10 \mathrm{MPa}$ and $70 \mathrm{MPa}$ ). Some laboratory tests carried out along the schistosity planes show values of the cohesion which vary between $0 \mathrm{MPa}$ (residual cohesion) and $0.28 \mathrm{MPa}$ (peak cohesion) (Lunardi, 1980).

During the excavation of the safety gallery, the RQD values of the ground have been recorded and exhibit a very large variation.

Feedback from the road tunnel excavation suggests that the water amount is very low and well localized.

\subsection{Excavation and support techniques in the Fréjus road tunnel}

The works have been executed over a total length of $12500 \mathrm{~m}$ (Levy et al., 1981). The excavation of the section was carried out in one step by drilling and blasting. The average length of the excavation step was between 3.50 and $4.50 \mathrm{~m}$. After the excavation, the execution of the invert was carried out at a distance of 300 to $400 \mathrm{~m}$ from the tunnel face. A soft support consisting in 20 punctually anchored rockbolts per linear meter was installed. The length of the bolts is of $4.65 \mathrm{~m}$, the diameter of $20 \mathrm{~mm}$ and the strength of $450 \mathrm{MPa}$. A wire grid $(10 \mathrm{~cm} \times 10 \mathrm{~cm} \Phi 5 \mathrm{~mm})$ was also installed to avoid rock debris to fall down. Buckling of the schistosity planes was observed at the West part of the vault where schistosity planes are tangent to the tunnel wall. The concreting operations of the final cast-in-place lining were executed at $600 \mathrm{~m}$ from the tunnel face (which corresponds to about 107 days after the excavation).

\subsection{Mechanized excavation technique of the Fréjus safety gallery}

The first 650 meters from the French portal of the safety gallery were excavated by conventional drill and blast methods. The rest of the safety gallery was excavated with a single shield TBM. The TBM was firstly used to excavate the $6.5 \mathrm{~km}$ of the French part of the 
tunnel. Then it was used to excavate the tunnel through the Italian part. The geological context of the safety gallery is similar to that of the road tunnel.

A single shield TBM for hard rock with longitudinal support was chosen for performing the excavation. The length of the shield is of $11.2 \mathrm{~m}$ and the maximal thrust force is about 75 $300 \mathrm{kN}$ in service conditions. The shield has a diameter of $9.37 \mathrm{~m}$ and a conicity of $60 \mathrm{~mm}$ which permits to accommodate the convergences. The cutting head has a diameter of $9.46 \mathrm{~m}$ with a nominal overcutting of $90 \mathrm{~mm}$ at the crown. However, the overcutting can be increased to $190 \mathrm{~mm}$ (medium size) and to $290 \mathrm{~mm}$ (large size). The excavation began with the nominal overcutting. The medium size overcutting was activated around chainage 1635. At chainage 2929 the nominal overcutting was activated again. Before facing up the second zone of strong convergences (see section 3.1), the medium size overcutting was activated once again at chainage 4346.

The lining is composed of concrete rings made of precast segmental lining of $40 \mathrm{~cm}$ thickness. The average length of a ring is $1.80 \mathrm{~m}$ and the inner diameter is $8.20 \mathrm{~m}$. The concrete of the segmental lining is class C45/55 (EuroCode 2). A universal ring constituted of $6+1$ elements has been used ( 4 standard segments, two counter keys and one key segment).

After the excavation and the installation of the concrete ring, the annular gap between the lining and the ground was filled with mortar and gravel. A first lay of mortar C3/5 (Eurocode 2) was injected through the shield in the lower part of the section on a $100^{\circ}$ wide zone. This task was followed by the gradual injection of the gravel through the segmental lining in the remaining portion of the annular gap. The onsite observations concluded that the gap was completely filled around the installation of ring n-7 ( $n$ being the closest ring to the face) (Fig2). To improve the backfilling technique and to remedy to some injection problems encountered in the vault, a new method consisting in a mortar-gravel-mortar filling ('sandwich technique') was adopted from chainage 1763 . The injection of the $60^{\circ}$ wide upper zone with mortar improved the backfilling process.

\section{Fig2. Backfilling technique of the annular gap after Vinnac (2012)}

\section{Study of the monitoring data retrieved during the excavation of the tunnels}

\subsection{Monitoring data and data processing in the road tunnel}

Convergence measurements were monitored in 127 sections along the tunnel. Monitored sections are in average $30 \mathrm{~m}$ spaced. Measurements are carried out by using invar type alloy wire until the installation of the final lining. At that moment the average rate of convergence is $0.2 \mathrm{~mm} /$ day.

Fig3. shows a typical convergence curve. The largest convergence generally occurs along the direction defined by targets 2 and 4 which is quasi perpendicular to the schistosity planes. This large convergence is attributed to the buckling of the schistosity planes. Convergence along direction defined by targets 1 and 4 is parallel to the tunnel invert. In some of the sections, convergence along direction 1-3 was also monitored. However, convergence data 
along direction 1-3 have been recorded over a shorter period of time and are missing in many sections.

Fig3. Convergence curves and schematic position of the targets in section 13 (chainage 1998)

The semi-empirical law proposed by Sulem et al. (1987), (equation 1) has been used in the analysis of convergence data of the road tunnel (De la Fuente et al., 2017).

$$
C(x, t)=C_{\infty x}\left[1-\left(\frac{X}{x+X}\right)^{2}\right]\left\{1+m\left[1-\left(\frac{T}{t+T}\right)^{n}\right]\right\}
$$

where $C_{\infty x}$ represents the instantaneous convergence obtained in the case of an infinite rate of face advance (no time-dependent effect), $X$ is a parameter related to the distance of influence of the face, $T$ is a parameter related to the time-dependent behavior of the system (rock mass - support), $m$ is a parameter which represents the relationship between the longterm total convergence and the instantaneous convergence and $n$ is a form-factor which is often taken equal to 0.3. By fitting the convergence data, it is possible to distinguish the total long-term convergence $C_{\infty x}(1+m)$ from the instantaneous convergence $C_{\infty x}$ which takes place in each section. In convergence data fitting it is important to account for the "lost convergence" $\Delta C$ which is the convergence which takes place between the face excavation and the beginning of convergence monitoring (at a distance from the face $x_{0}$ and at a time elapsed from the face excavation $t_{0}$ ):

$$
\Delta C(x, t)=C(x, t)-C\left(x_{0}, t_{0}\right)
$$

The study shows that parameters $X, m$ and $n$ can be considered the same for the fitting of almost all of the sections in the tunnel $(X=10.5 \mathrm{~m}, m=4.5$ and $n=0.3)$. The choice of these parameters is in accordance with previous studies found in the literature (Sulem et al, 1987, Panet 1996, Guayacan et al, 2018). As suggested by Guayacan et al. 2018, the parameter $X$ is taken equal to $0.9 D$ where $D$ is the diameter of the tunnel. Parameters $T$ and $C_{\infty x}$ are fitted for every single section and direction considering the strong heterogeneity of the magnitude of convergences and of the mid-term convergence rate observed from in the road tunnel. A very good approximation of convergence data is obtained as shown in the examples in Fig4. We can observe that $T$ which controls the convergence rate exhibits a significant variability along the tunnel length and varies between 0.5 and 5 days for direction 2-4 (Fig5.). However, some "homogeneous" zones corresponding to similar values of the instantaneous convergence along direction 2-4 have been identified (Fig6.).

Fig4. Convergence evolution along direction 2-4 and fitting with the law of de Sulem et al. (1987) for section 17 at chainage 2113 (a) and section 118 at chainage 5080 (b). On the left in function of time and on the right in function of the distance to the advancing face 
Fig6. Evolution of $C_{\infty x}$ along direction 2-4 along the road tunnel (the red dotted lines represent the average convergence value for each zone) (a). Evolution of the anisotropy ratio $\beta$ along the road tunnel (the blue dotted lines represent the average convergence value for each zone) (b). After De la Fuente et al., (2017)

As it has been highlighted by Lunardi (1980) the largest convergences are not necessarily related to the largest overburden. For instance, overburden in zone $\mathrm{C}$ is smaller than in zone $\mathrm{B}$ but convergences are larger. The magnitude of the convergences is not only influenced by the overburden but also by the existing sets of fractures and by the content of phyllosilicates (muscovite and chlorite) and graphite in the rock mass.

Fig6. shows the anisotropy ratio between the instantaneous convergence along direction 24 and the instantaneous convergence along direction 1-4: $\beta=C_{\infty \times 2-4} / C_{\infty \times 1-4}$ for each section along the road tunnel. The "homogeneous zones" cannot be characterized by the anisotropy ratio as this parameter varies significantly along the tunnel.

\subsection{Monitoring data and data processing in the safety gallery}

During the excavation of the safety gallery, an important survey campaign was carried out: convergence data was retrieved at the inner face of the concrete ring; convergence data of the ground was measured with hydraulic jacks through the TBM shield, these hydraulic jacks measure the existing gap between the shield of the TBM and the tunnel wall; cracks observation was carried out; monitoring data was obtained from strain gauges embedded in the segmental lining of 49 sections which can provide information on the state of stress in the lining and other information was also obtained during the excavation of the safety gallery such as the thrust force and the torque exerted over the cutting head of the TBM. These measurements have three objectives: the collection of information to improve the excavation technique and/or the lining design during the excavation of the gallery, the prevention of risks that might be encountered during tunnel execution and the creation of a useful data base in order to back analyze the tunnel behavior.

Monitoring data from strain gauges represent the most reliable source of information. Six pairs of strain gauges were embedded in the segmental lining (Fig7.). Each pair represents the response of the extrados and intrados fibers of the segmental lining. It should be noted that, unfortunately, many interruptions exist in the recorded strain data.

\section{Fig7. Distribution of the strain gauges in the ring 1821, Chainage 3917 (raw data)}

Fig8. shows some typical results of the data processing of the safety gallery as described in detail in De la Fuente et al 2017. The maximal compression stress recorded in the lining along the tunnel is plotted and compared with the evolution of the lateral friction exerted by the ground over the TBM and values of RQD retrieved from the gallery. Fig8. also shows the "homogeneous" zones as previously identified in the road tunnel which are overlaid here onto the safety gallery data. Monitoring data from both tunnels are in accordance. The areas of the road tunnel which exhibit larger convergence correspond to the zones of the gallery with higher stress level in the lining. We can observe that in the areas where lateral friction exerted by the ground over the TBM is higher, the values of the RQD are lower than the average of 70 
$\%$. This can mainly be observed around chainage 1550 which corresponds to a very fractured rock. However, the RQD index is only representative of the degree of fracture and cannot describe the overall quality of the rock. Around chainage 1550 the highly fractured zone can also be identified with the increasing lateral friction over the TBM. The maximum friction which is observed around chainage 6430 is the result of the resumption of the excavation after a standstill of 126 days.

Fig8. Lateral friction exerted by the ground over the TBM skirt, maximal compression stress measured in the lining (the distance to the excavation face at which the stress has been retrieved can be found next to each point representing the stress state) and RQD values of the ground retrieved from the East or the West side of the vault during the excavation, as a function of chainage in the safety gallery (De la Fuente et al., 2017)

\section{Numerical simulations of the Fréjus road tunnel}

\subsection{Anisotropic time-dependent constitutive model}

In the numerical simulations of the Fréjus road tunnel, the assumed constitutive behavior for the ground is visco-elasto-plastic and anisotropic. This constitutive model has been successfully used by Tran-Manh et al. (2015) to reproduce the response of Saint-Martin-LaPorte access adit within the framework of Lyon-Turin railway project. This model considers one family of weakness planes embedded in an isotropic rock matrix. It combines the CVISC model which describes the behavior of the rock matrix and the ubiquitous joints model which introduces the anisotropy resulting from the presence of weakness planes (Fig9.).

Fig9. Ubiquitous joint model in a viscoplastic matrix

CVISC model considers an elasto-plastic volumetric behavior and a visco-elasto-plastic deviatoric behavior driven by a Burgers visco-elastic element and a plasticity element. The model can describe both instantaneous and delayed deviatoric strains (Boidy et al., 2002). This model is implemented in FLAC ${ }^{3 \mathrm{D}}$ and has been previously used in many numerical simulations (e.g. Barla et al. 2007, 2008, 2010, 2011, Pellet 2009, Sharifzadeh et al. 2013, Hasanpour et al. 2015).

The presence of discontinuities such as schistosity planes is taken into account by means of the "ubiquitous joints model". It consists in a set of joints of a given orientation which pass through any point in the rock mass. These joints are activated if the yield criterion is reached (Coulomb criterion with tension cut-off). The ubiquitous joint approach permits to model a jointed rock-mass (Kazakidis and Diederichs, 1993). This model has been largely used in the simulation of underground excavations (Cartney 1977, Li et al. 2003, Plana et al. 2004, Russo et al. 2009, Wang \& Huang 2009, 2013).

This constitutive model is characterized by 13 constitutive parameters. The mechanical behavior of the solid matrix is described by 9 parameters (elastic bulk modulus $K$, Kelvin shear modulus $G_{K}$, Kelvin dynamic viscosity $\eta_{K}$, elastic shear modulus $G_{M}$, Maxwell dynamic viscosity $\eta_{M}$, cohesion $c$, friction angle $\phi$, dilation angle $\psi$, and tension limit $\sigma_{t}$ ). The behavior of the weak planes is described by 4 parameters (joint cohesion $c_{j}$, joint friction angle $\phi_{j}$, joint dilation angle $\psi_{j}$ and joint tension limit $\sigma_{t j}$ ). Two additional geometric 
parameters describe the orientation of the weak-plane (dip angle and dip direction of weakness plane).

\subsection{Identification of the envelope of the convergences in the Fréjus road tunnel}

As shown in $\$ 3.1$ some "homogeneous" zones in terms of the amplitude of the convergences have been identified (De la Fuente et al., 2017). The present chapter aims at reproducing the behavior observed in the "homogeneous" zone A. Along this area of the tunnel, a moderate buckling phenomenon was observed during construction. Fixing $\mathrm{n}=0.3$, the parameters $\left(T, X, C_{\infty x}, m\right.$ ) have been obtained for each section from the fitting of the convergence data with the convergence law of Sulem et al., (1987).

With these values of parameters $\left(T, X, C_{\infty x}, m\right)$, convergence curves are plotted in Fig10. assuming a constant face advance rate of $5.6 \mathrm{~m} /$ day for all sections. Therefore, the various convergence curves can be better compared as the effects of the arrests of the face advance are removed. In doing so, it is assumed that the parameters of the convergence law do not depend on the advancing rate of excavation. Furthermore, all the curves are plotted considering that the first measurement is retrieved at a distance of $4.5 \mathrm{~m}$ from the tunnel face which corresponds more or less to the average length of one step of excavation. This means that the installation of the monitoring targets is assumed to be done 0.8 days after the opening of the section. Within "zone A", section 12 (chainage 1976) exhibits the largest convergence, whereas section 29 (chainage 2322) exhibits the smallest one.

\section{Fig10. Convergence curves in the "homogeneous zone A" along direction 2-4 (a) and along} direction 1-4 (b)

\subsection{Back-analysis of the short-term response of the Fréjus road tunnel}

A 3D numerical simulation is carried out with $\mathrm{FLAC}^{3 \mathrm{D}}$ in order to simulate the behavior of the Fréjus road tunnel. Fig11. shows the geometry of the model. The model is large enough in order to simulate the excavation and minimize boundary effects. Far field boundaries are placed at a distance of 28 radii (considering the vault radius) and the length of the model in the axial direction is $90 \mathrm{~m}$. Mesh is discretized into small elements of $0.45 \mathrm{~m}(<1 / 10 \mathrm{R})$. The in-situ stress state is initially imposed everywhere in the domain (average depth of $1067 \mathrm{~m}$ and average specific weight of the ground of $27 \mathrm{kN} / \mathrm{m}^{3}$ ). Gravity effects are neglected. The step of excavation is $4.5 \mathrm{~m}$ and an advancing rate of $5.6 \mathrm{~m} /$ day is imposed in the computations in accordance with the average values observed during the excavation of the tunnel. The coordinates of the targets in the simulations are the average coordinates of all the targets along the tunnel (Fig12.).

\section{Fig11. Geometry of the model (a). Detail of the displacements around the tunnel during its excavation for section 12 (chainage 1976) (b). $\mathrm{R}$ is the radius of the vault of the excavated tunnel $(5.8 \mathrm{~m})$}

Fig12. Geometry of the tunnel and average position of the targets considered in the numerical model

The possible interaction between the two tunnels has been disregarded. This assumption is based on the fact that the axes of the tunnels are at a distance of $50 \mathrm{~m}$. From extensometers 
data, the maximal thickness of the plastic zone around the road tunnel was estimated of around $10 \mathrm{~m}$. The two tunnels are thus sufficiently far from each other so that the assumption of no interaction is acceptable.

In order to guarantee a quasi-static mechanical equilibrium, it is necessary to choose a sufficiently small time step (Billaux and Cundall, 1993). The maximum creep time step $\Delta t_{\max }^{c r}$ is here estimated as the ratio of the material viscosity to the shear modulus $\Delta t_{\max }^{c r} \leq$ $\min \left(\frac{\eta_{K}}{G_{K}}, \frac{\eta_{M}}{G_{M}}\right)$ (ITASCA, 2011).

The dip direction of the schistosity planes is assumed parallel to the tunnel axis and its dip angle is fixed at an average value of $45^{\circ}$ for the numerical simulations. The support composed of 20 rockbolts $/ \mathrm{m}$ is simulated by introducing cable structural elements which are punctually anchored to the tunnel wall and to the ground. Each cable can yield in tension but cannot resist a bending moment. The length of the rockbolts is $4.65 \mathrm{~m}$ with a diameter of $20 \mathrm{~mm}$ and a strength limit of $450 \mathrm{MPa}$.

Sections showing the largest convergence and the smallest convergence are back-analyzed by using the above constitutive model, (Fig13.) (see also De la Fuente et al., 2018a). A horizontal pressure coefficient $K_{0}$ of 1.4 has been assumed in accordance with the value adopted in the design project of the Fréjus safety gallery. The values of the mechanical parameters of the joints are fitted to best reproduce the anisotropy of the convergence measurements and are identical in both cases $\left(c_{\mathrm{j}}=0,15 \mathrm{MPa}, \phi_{j}=20^{\circ}, \psi_{j}=5^{\circ}\right.$ and $\sigma_{t j}$ $=0.01 \mathrm{MPa}$ ). The values of some of the parameters of the rock matrix are assumed the same in both sections: $E=40 \mathrm{GPa}$ (mean value obtained from measurements of the Young's modulus in the parallel direction to the schistosity planes by Beau et al. (1980)), $\psi=15^{\circ}$ (value adopted in the design project of the Fréjus safety gallery), $\phi=40^{\circ}$ (fitted value), $\sigma_{t}=\sigma_{c} / 10$ and $v=0.3$ (value adopted in the design project of the Fréjus safety gallery). The four other parameters of the matrix are fitted and differ from one section to another, Fig13. The largest values (.) max $_{\text {ox }}$ of parameters $c, \eta_{K}, G_{K}$ and $\eta_{M}$ are assigned to the smallest convergence (section 29) and vice versa. The in situ observed behavior is accurately reproduced with the model.

Fig13. Back analysis of convergence data of section 29 (chainage 2322) ( smallest convergence) and schematic average distribution of the targets (right) in the section (a) back analysis of convergence data of section 12 (chainage 1976) (largest convergence) and schematic average position of the targets (right) in the section (b)

The developed plastic zones around the tunnel and the rockbolts stress state 90 days after the excavation of the tunnel are shown in Fig14. (a) for section 12 and Fig14. (b) for section 29. It is observed that the extent of the plastic area is much more important in the direction perpendicular to the weak planes. It brings out the important role of the weak plane yield criterion in the constitutive model.

Fig14. Plastic zones around the tunnel excavation and stress state in the rockbolts in section 12 (chainage 1976) (largest convergence) (a) and plastic zones around the tunnel excavation and stress state in the rockbolts in section 29 (chainage 2322) (smallest convergence) (b) .

Red zones are the areas where the matrix is in plastic state, green zones are the areas where joints are in plastic state and blue zones are the areas where matrix and joints are in plastic state at the same time. Rockbolts drawn in red have reached the elastic limit 
Sections within zone A can be simulated by fitting the cohesion of the joints $c_{\mathrm{j}}$ and a variability parameter $\alpha$ with values between 0 and 1 , which can be seen as a variable describing the degree of damage of the ground, taking as reference values 0 for section 19 giving the smallest convergence and 1 for section 12 giving the largest one. This parameter permits to simply evaluate the time-dependent parameters of the matrix and the matrix cohesion for all sections in zone A (Equation 3). The variability index $\alpha$ is evaluated for each section by fitting the convergence measured along direction 1-4. As this direction is subparallel to the weakness planes, it is assumed that the convergence measurements along 1-4 are representative of the rock matrix behavior. Once parameter $\alpha$ is evaluated, $c_{\mathrm{j}}$ is fitted from the convergence measurements along direction 2-4. The stronger the convergence along 2-4, the stronger the anisotropy of the section and the lower the value of $c_{\mathrm{j}}$. The other parameters remain the same for all the sections.

$$
\begin{gathered}
c=c_{\min } \alpha+(1-\alpha) c_{\max } \\
G_{k}=G_{k_{\min }} \alpha+(1-\alpha) G_{k_{\max }} \\
\eta_{k}=\eta_{k_{\min }} \alpha+(1-\alpha) \eta_{k_{\max }} \\
\eta_{M}=\eta_{M_{\min }} \alpha+(1-\alpha) \eta_{M_{\max }}
\end{gathered}
$$

The comparison between computed and measured convergences along directions 2-4 and 1-4 for the various sections in zone A is shown in Fig15. The fit for the rest of the sections within zone A can be found in Online resource (De la Fuente et al., 2018b). The agreement of the numerical results with the observed field measurements over a period of 90 days is very good. A quasi-constant convergence rate is reached after four or five months because of the presence of a Maxwell viscous element $\eta_{M}$ in the rheological model. $\alpha$ and $c_{\mathrm{j}}$ take different values for each section. The values of $c_{\mathrm{j}}$ retained for the numerical simulations are of the same order of magnitude as the values of the cohesion of the schistosity planes measured from laboratory tests. Some of the sections which exhibit very strong anisotropy of the convergences are simulated by assuming cohesionless joints $\left(c_{\mathrm{j}}=0\right)$. The values of $\alpha$ and $c_{\mathrm{j}}$ for each section are reported in Tab1. Within the studied range of values assigned to the parameters of the constitutive model, sections showing an anisotropy ratio $\left(\beta=C_{\infty \times 2-4} /\right.$ $\left.C_{\infty x 1-4}\right)$ larger than 4 cannot be properly simulated (sections 19, 20 and 45).

\section{Fig15. Back analysis of convergence data of sections within zone A (from chainage 1905 to chainage 2723)}

\section{Tab1. Fitted values of $\alpha$ and $c_{\mathrm{j}}$ for each section within zone A}

A linear correlation can be found between the variability index $\alpha$ (fitted along direction 14 ) and a parameter $\xi$ as defined in equation 4 . $\xi$ is a function of the instantaneous convergence evaluated in the semi-empirical convergence law along direction 1-4 $\left(C_{\infty \times 1-4}\right)$ (see section 3.1) (Fig16.). $C_{\infty x 1-4 \min }$ is the instantaneous convergence along direction 1-4 for section 29 (showing the smallest convergences) and $C_{\infty \times 1-4 \max }$ is the instantaneous convergence along direction 1-4 for section 12 (showing the largest convergences).

$$
\xi=\left(\frac{C_{\infty \times 1-4}-C_{\infty \times 1-4 \min }}{C_{\infty \times 1-4 \max }-C_{\infty \times 1-4 \min }}\right)^{\frac{1}{3}}
$$


Fig16. Linear correlation between $\alpha$ (variability index introduced in the model parameters) and $\xi$ (variability index evaluated on convergence measurements)

\subsection{Prediction of the long-term response of the Fréjus road tunnel}

We have shown above that the proposed constitutive model is able to correctly reproduce the field data. It is always a challenging question to assess the performance of a model that has been calibrated on data recorded during few months for predicting the very long-term behavior of a structure. It is however an interesting point to test the predictive capacity of the model. Therefore, a numerical prediction of the average long-term behavior (40 years) of the Fréjus road tunnel has been carried out. We first identify a typical section (section 23 in chainage 2267) showing an average response within zone A. The values of the mechanical parameters which govern section 23 short-term behavior are: $\alpha=0.6$ and $c_{\mathrm{j}}=0.2 \mathrm{MPa}$. With this set of parameters, we extrapolate the long-term convergences of section 23 at 40 years, assuming that the final support is not installed and by using the empirical convergence law fitted in the previous chapter $\left(X=10.5 \mathrm{~m}, m=4.5, n=0.3, C_{\infty \times 2-4}=26.1 \mathrm{~mm}, C_{\infty x 1-4}=\right.$ $11.0 \mathrm{~mm}, T_{2-4}=3.3$ days, $T_{1-4}=1.9$ days). Finally, we perform a numerical analysis of section 23, using the proposed constitutive model and without the final support (Fig17). It was obtained that with the chosen constitutive model, it is not possible to find a single set of parameters able to reproduce short-term convergences and mid and long-term convergences at the same time. This is due to the linear Maxwell element in the rheological model which leads to constant deformation rate in the long-term and therefore cannot reproduce the decreasing convergence rate of the empirical convergence law. For this reason, in an attempt to keep the model as simple as possible, two sets of parameters are used in the same numerical simulation. The first set of parameters $\left(\alpha=0.65\right.$ and $\left.c_{\mathrm{j}}=0.2 \mathrm{MPa}\right)$ is used to fit short-term convergences on the average behavior of the road tunnel. The short-term convergences are considered to be the ones that occur before the installation of the final concrete lining (107 days after the excavation of the section). The blue vertical line shown in Fig17. (a) separates the short-term convergences from the mid and long-term convergences. A second set of parameters is used to reproduce the long-term convergences. Only parameter $\eta_{M}$ of the second set is modified as compared to the first one, $\eta_{M}$ is multiplied by 23 (Fig17.).

\section{Fig17. Medium-term (a) and long-term (b) back analysis of convergence data of section 23 within zone A (chainage 2267)}

Finally, we use the identified parameters of the model for the simulation of the Fréjus road tunnel with the installation of the final lining system in order to study the long-term ground/lining interaction, Fig18. The installation of the final lining is carried out in two steps: installation of the invert at $350 \mathrm{~m}$ from the excavation face and installation of the final lining at $600 \mathrm{~m}$ from the excavation face (107 days after the excavation of the section). In consequence, the activation of the second set of parameters coincides with the installation of the final lining. With this approach, the effect of the installation of the final lining on the ground behavior is explicitly taken into account (the final lining exerts a pressure on the rock mass that can lead to the progressive closure of the existing joints of the ground which will therefore affect the time-dependent behavior of the rock mass). A long-term Young's modulus for the concrete of $11 \mathrm{GPa}$ is used in the numerical simulations. This modulus 
corresponds to one third of the secant Young's modulus $\left(E_{c m}\right)$ after 28 days of a C35/45 concrete after Eurocode 2 as considered in common practice.

\section{Fig18. Geometry of the model: Fréjus road tunnel and its final lining}

Fig19. (a) shows the computed maximal (in absolute value) principal stress in the vault of the road tunnel after 40 years. One of the highest value takes place in the West side of the vault where the strongest convergence occurs. This stress reaches $13 \mathrm{MPa}$ after 40 years (Fig19. (b)). This value is slightly smaller than the designed uniaxial compression strength of a C35/45 concrete estimated at $17 \mathrm{MPa}$. Measurements of stresses in the lining have been carried out in the road tunnel with a flat-jack test (between chainages 1800 and 2200) in recent years. In the East side of the vault values ranging from 5 to $32 \mathrm{MPa}$ with an average of $16 \mathrm{MPa}$ have been retrieved. These data are thus in accordance with the numerical predictions. From the numerical simulations, we obtain a constant convergence rate of 0.25 $\mathrm{mm} /$ year in the lining. The in-situ monitoring convergence rates of the lining range from 0.15 to $0.3 \mathrm{~mm} /$ year (data retrieved between chainages 1800 and 2200 from year 1980 to year 1997). The computed results and the in situ data are thus in a rather acceptable accordance.

Fig19. Plot of the computed maximal principal stress in the vault of the road tunnel after 40 years (a). Highest computed stress in the vault as a function of time (b)

\section{Prediction of the behavior of the Fréjus safety gallery}

\subsection{Interpretation of stress data retrieved from the segmental lining}

Monitoring data from pairs of strain gauges embedded in the segmental lining of the safety gallery is first analyzed. The stress state in the lining can be obtained from strain data by assuming an elastic behavior of the concrete. A mid-term Young's modulus of $20 \mathrm{GPa}$ is considered for the concrete.

The segmental lining is submitted to a loading which is the result of the combination of two mechanisms that take place during the excavation of the tunnel:

- Instantaneous buckling: Schistosity planes that are tangent to the tunnel wall tend to buckle during the excavation. This buckling mechanism takes place projecting rock blocks that are detached from the tunnel wall and impact the TBM and the installed lining. Within the first meters after the TBM passage ( $9 \mathrm{~m}$ to $20 \mathrm{~m}$ from the tunnel face), the annular gap is not completely filled up with the backfilling material. As a consequence, the segmental lining is not protected and the detached rock blocks impact the lining favoring the generation of cracks in the concrete.

- Time-dependent convergence of the ground: The time-dependent behavior of the ground results in a time-dependent loading of the lining during and well after the tunnel excavation.

These two mechanisms are generally combined and difficult to separate. However, in the present work, an attempt to identify the main mechanisms acting in each monitored section is carried out. From the stress data, the instantaneous buckling effect is identified and separated 
from the effect of a time-dependent response of the ground which is the main topic addressed in this paper.

Fig20. shows stress data in function of time in ring 1257 (chainage 2902). Measurements resulting from instantaneous buckling can be identified in those pairs of gauges (one at the intrados and one at the extrados) showing an opposite behavior (one gauge is compressed while the other one exhibits tensile stresses). In Fig20. (a), dotted lines represent stress measurements from those pairs of gauges embedded in a segmental lining which is affected by the impact of instantaneous buckling. In Fig20. (a), the stress measurements recorded by the other sensors and mainly controlled by the time-dependent convergence of the ground are also plotted. Some tensile stresses are nevertheless observed on data plotted in Fig20 (a). They may be due to the efforts induced by the longitudinal support of the TBM which is jacked against the segmental lining in order to advance. Within the first meters after the TBM passage, the annular gap is not completely filled up with the backfilling material and as a consequence the thrust cylinders of the machine may induce important tensile efforts in the segmental lining.

Fig20. Evolution of the stress state in function of time in section 1257 (chainage 2902) (a) schematic representation of the position of the strain gauges within the concrete ring (b) (the evolution of the time-dependent convergence of the ground is in solid line whereas the evolution of convergence originated from instantaneous buckling is in dashed line)

\subsection{Prediction of the short-term response of the Fréjus safety gallery}

A 3D numerical simulation has been carried out with FLAC ${ }^{3 D}$ software in order to simulate the behavior of the Fréjus safety gallery. Fig21. shows the geometry of the numerical model. Far field boundaries are placed at a distance of 36 radii (considering an outer radius of the gallery R of $4.5 \mathrm{~m}$ ) in order to minimize boundary effects. The length of the model is $90 \mathrm{~m}$. An average value of $190 \mathrm{~mm}$ is assumed for the overcutting and an eccentricity of the lining $(0.095 \mathrm{~m})$ with respect to the TBM cutting head is considered. The size of the elements at the tunnel wall is of $0.6 \mathrm{~m}$. The in-situ stress state is initially imposed everywhere in the domain (average depth of $1067 \mathrm{~m}$ and average specific weight of the ground of $27 \mathrm{kN} / \mathrm{m} 3$ ). Gravity gradient effects are disregarded. The step of excavation is $1.8 \mathrm{~m}$ which corresponds to the transversal length of a segmental lining. An advancing rate of $12.9 \mathrm{~m} /$ day is considered in accordance with the average advancing rate observed during the excavation of the safety gallery. In order to simplify the model and to focus on long-term behavior it was chosen not to explicitly simulate the TBM excavation process.

\section{Fig21. Scheme of the geometry of the lining and the backfilling in the safety gallery (a) geometry of the numerical model of the safety gallery (b)}

Buckling phenomena are not considered in the present study. The unsupported spam is taken equal to $19.8 \mathrm{~m}$. It is assumed that the annular gap is completely filled up with the backfilling material only at this distance of $19.8 \mathrm{~m}$. A "sandwich" type backfilling composed of gravel and mortar is considered in the simulations. The gravel and the mortar are assumed to have an elastic response with a Young's modulus of 100 and $500 \mathrm{MPa}$ respectively. The installed elastic lining has a thickness of $40 \mathrm{~cm}$ and its Young's modulus is $20 \mathrm{GPa}$. The choice of this value has been made as it corresponds to a commonly use mid-term Young's 
modulus in civil engineering practice for the case of a C45/55 concrete. The backfilling and the lining are active since their installation at a distance of $19.8 \mathrm{~m}$ from the tunnel face.

The ground behavior as identified from the study of the road tunnel is extrapolated for the simulation of the safety gallery. From preliminary computations, it was obtained that assuming the same values for the constitutive parameters as those calibrated on the road tunnel leads to an overestimation of the stresses in the lining. As the lining is placed at a distance of more than two diameters to the tunnel face, its response is mainly controlled by the time-dependent behavior of the rock mass. Therefore, the instantaneous constitutive parameters are kept the same in both tunnels and the time-dependent parameters $\left(\eta_{M}, \eta_{k}, G_{k}\right)$ are adjusted. In the sake of keeping the model as simple as possible, these time-dependent ground parameters are simply multiplied by a factor $F$ for simulating the response with TBM excavation. The observation that with TBM excavation, the time-dependent deformation of the ground is reduced is attributed to the fact that, when tunneling with a TBM, the ground is less damaged than when tunneling by drilling and blasting. In order to assess how the time dependent parameters of the rock should be adjusted for the safety gallery, some preliminary numerical tests have been performed. Parameters $G_{k}$ and $\eta_{k}$ control the short-term response. It was obtained that if $G_{k}$ is adjusted with a larger value of $F$ than $\eta_{k}$, short-term convergences will be overestimated. On the other hand, mid-term and long-term response are mostly controlled by parameter $\eta_{M}$. Here again, it was obtained that by taking of the same value of $F$ as the one applied to short-term creep parameters gives the best results to simulate mid-term and long-term ground convergences. Consequently, the same value of $F$ was adopted for all the time-dependent parameters for obtaining numerical results in good accordance with monitoring data. It is found that the Fréjus safety gallery response can be correctly reproduced by taking a value of $F$ equal to 15 . If $F$ is taken equal to 1 , the average maximal hoop stress obtained with the model parameters describing the average behavior of the road tunnel $\left(\alpha=0.65\right.$ and $\left.c_{\mathrm{j}}=0.2 \mathrm{MPa}\right)$ clearly overestimates the state of stresses in the lining (Fig22.).

\section{Fig22. Fitting of the parameter $F$ with the average maximal hoop stress obtained with the model parameters describing the average behavior of the road tunnel $\left(\alpha=0.65\right.$ and $c_{\mathrm{j}}=0.2$ $\mathrm{MPa})$}

Fig23. shows the envelope of the predicted maximal hoop stresses (dotted lines) in the lining. This maximal stress state corresponds to the zone of stress concentration in the lining (Fig24.). Following the sign convention of FLAC ${ }^{3 \mathrm{D}}$, compressions are taken negative, thus compressive stresses correspond to the minimal principal stresses as plotted in Fig24. We can observe that the maximal compression is located at the invert as the mortar injected in the annular gap tends to lead to stress concentration in this area (see Fig24.). These computations are performed by taking the constitutive parameters calibrated on the sections of the road tunnel which exhibits the highest and the lowest convergence. We can observe that the maximal hoop stresses (resulting only from the time-dependent behavior of the ground) retrieved from the different sections of the safety gallery in zone A fall within the predicted envelope. The average maximal hoop stress obtained with the model parameters describing the average behavior of the road tunnel $\left(\alpha=0.65\right.$ and $\left.c_{\mathrm{j}}=0.2 \mathrm{MPa}\right)$ is also plotted in Fig23. (black thick solid line).

Fig23. Predicted envelope of maximal hoop stress in the safety gallery and retrieved maximal hoop stress from sections within zone A 
Fig24. Minimal principal stress (maximal compression) in the lining after 3 months (maximal constitutive parameters for the ground are assumed in the computation)

Similarly, Fig25. shows the predicted envelope of the minimal hoop stresses in the lining. We observe that the minimal hoop stresses retrieved from the safety gallery are predicted with less accuracy than the retrieved maximal stresses. The numerical results tend to overestimate the minimal stresses and tensile stresses are not obtained.

\section{Fig25. Predicted envelope of minimal hoop stress in the safety gallery and retrieved minimal hoop stress from sections within zone A}

\subsection{Prediction of the long-term response of the Fréjus safety gallery}

The above numerical simulations show an accurate short-term prediction of the safety gallery response as a good approximation of field data has been achieved. However, the question arises concerning the long-term predictive capacity of the numerical model as applied to the safety gallery. Obviously no long-term data are available at the moment, therefore only blind predictions can be performed. A numerical prediction of the average long-term behavior (40 years) of the Fréjus safety gallery has been carried out. For this purpose, we consider the constitutive parameters of the model corresponding to the average behavior (see Fig23.) as used for the short-term predictions. For the segmental lining, we take a constant Young modulus of $12 \mathrm{GPa}$ corresponding to the long-term behavior of the concrete. This modulus corresponds to one third of the secant Young's modulus $\left(E_{c m}\right)$ after 28 days of a $\mathrm{C} 45 / 55$ concrete after Eurocode 2 as considered in common practice. The mechanical properties of the mortar and the gravel are kept unchanged. The numerical computations lead to a maximal compressive stress located at the invert of about $25 \mathrm{MPa}$ in the lining after 40 years (see Fig26.). This prediction looks reasonable and gives confidence to the predictive capability of the proposed approach, however, it can only be confirmed when long-term data will be available.

Fig26. Highest computed compressive stress as a function of time

\section{Conclusion}

The present work aimed at studying the behavior of tunnels excavated under squeezing conditions. Particular attention has been paid to the effect of the method of excavation on the response of the tunnel. For that, we have referred to the case study of the Fréjus road tunnel and of its safety gallery which are an example of two parallel tunnels excavated in complex conditions but with different methods. The Fréjus tunnel response which was excavated by drill and blast methods is compared to that of its safety gallery which was excavated with a TBM.

The instantaneous and the time-dependent behavior of the rock mass of the Fréjus road tunnel has been studied by means of a numerical back-analysis of the convergence measurements of the road tunnel. The constitutive model of the rock mass is visco-elastoplastic with weakness planes (ubiquitous joints model) in the direction of the schistosity of the ground in order to account for its anisotropy. A calibration method has been developed in order to properly fit most of the sections in one of the most complicated areas of the road 
tunnel. This method consists in the identification and in the back-analysis of the sections of the road tunnel showing the smallest and the larges convergences. The rest of the sections of the studied area can be fitted by adjusting the joints cohesion and a variability parameter which represents the magnitude of the convergences of the matrix. The limitations of the model in terms of anisotropy have been studied with this work as sections showing an anisotropy factor larger than 4 cannot be properly simulated.

Based on the extrapolation of the convergence law of Sulem et al. (1987) a prediction of the long-term convergences of the ground in an hypothetical unlined road tunnel has been carried out. These long-term convergences have been back-analyzed with the numerical model by using two set of parameters within the same numerical simulation: a first set of parameters used in order to back-analyze the short-term convergences and a second set of parameters used in the back-analysis of the long-term convergences. This is a first step to account for the evolution in time of the rock behavior and further development will enrich the constitutive model in the near future by considering non-linear viscous elements. Nevertheless, reasonable predictions of the stress state developed in the lining after 40 years have been obtained following this methodology.

An attempt to predict the response of the Fréjus safety gallery has been presented in this study. The behavior of the ground identified with the study of the road tunnel has been extrapolated to the parallel zones of the safety gallery. From the numerical results, it is observed that although instantaneous parameters can be assumed the same in both tunnels, the time-dependent constitutive parameters of the rock mass to be considered in the numerical model depend upon the excavation process. In practice, the shear modulus and the viscosity of the Kelvin element and the viscosity of the Maxwell element need to be multiplied by a factor $\mathrm{F}=15$ for the modelling of the TBM excavation (Fréjus safety gallery) as compared to drilling and blasting excavation process (Fréjus road tunnel). The reason for that stems from the fact that the damage induced in the rock by blasting effects is more important than the one induced by a mechanized excavation and the blocking of the ground by the rigid lining occurs in a very short time. The results of the prediction are very good in terms of the maximal hoop stress if compared to the retrieved field data ( 3 months of monitoring). However, the minimal hoop stress is slightly overestimated. With the same set of model parameters (except the consideration of a long-term Young's modulus of the concrete of the lining), the computations are pursued up to 40 years. It is obtained that the proposed model leads to reasonable longterm predictions which however cannot be confirmed in absence of long-term field data.

\section{Conflict of interest}

The authors declare they have no conflict of interest.

\section{References}

Barla, G. (2001) Tunnelling under squeezing rock conditions. Euro-summer-School in Tunnel Mechanics, Innsbruck 169-268

Barla G, Bonini M, Debernardi, D (2007). Modelling of tunnels in squeezing rock. ECCOMAS Thematic Conference on Computational Methods. Tunnelling (EURO:TUN 2007). Vienna, Austria, August 27-29 
Barla G, Bonini M, Debernardi D (2008) Time Dependent Deformations in Squeezing Tunnels. 12th International Conference of International Association for Computer Methods and Advances in Geomechanics (IACMAG). Goa, India

Barla G, Bonini M, Debernardi D (2010) Time Dependent Deformations in Squeezing Tunnels. International Journal of Geoengineering Case Histories 2(1):40-65

Barla G. Debernardi, D, Sterpi D (2011) Time-dependent modeling of tunnels in squeezing conditions. International Journal of Geomechanics ASCE, (December) 697-710

Beau J.-R., Cabanius J, Courtecuisse G, Foumaintraux D, Gesta P, Levy M, Neraud C, Panet M., Péra J., Tincelin E. \& Vouille G (1980). Tunnel routier du Fréjus: les mesures géotechniques effectuées sur le chantier français et leur application pour la détermination et l'adaptation du soutènement provisoire. Revue Française de Géotechnique, 12, 57-82 (in French)

Billaux, D, \& Cundall, P (1993) Simulation des géomatériaux par la méthode des éléments Lagrangiens. Revue française de Géotechnique, (63):9-21

Boidy E (2002) Modélisation numérique du comportement différé des cavités souterraines (Doctoral dissertation, Université Joseph-Fourier-Grenoble I)

Cartney SA (1977) The Ubiquitous Joint Method. Cavern Design at Dinorwic Power Station. Tunnels \& Tunneling 9:54-57

De la Fuente M, Sulem J, Taherzadeh R, Subrin D (2017) Traitement et rétro-analyse des auscultations réalisées dans le tunnel routier du Fréjus et sa galerie de sécurité lors de leurs constructions respectives. Congrés International AFTES 2017, Paris 155 (in French)

De la Fuente M, Taherzadeh R, Sulem J, Subrin D (2018a) Analysis and comparison of the measurements of Fréjus road tunnel and of its safety gallery. Eurock symposium 2018, Saint Petersburg v2 1143-1148

De la Fuente M, Taherzadeh R, Sulem J, Subrin D (2018b), online resource, Numerical backanalysis of the short-term convergence data of sections within zone A (from chainage 1905 to chainage 2723) in the Fréjus road tunnel ,Zenodo, doi: 10.5281/zenodo.1503642

Eurocode 2 (2005) Design of concrete structures

Guayacán-Carrillo L-M, Sulem J, Seyedi D M, Ghabezloo S, \& Armand G. (2018). Size Effect on the Time-Dependent Closure of Drifts in Callovo-Oxfordian Claystone. International Journal of Geomechanics, 18(10), 04018128

Hasanpour R, Rostami J, Barla G (2015) Impact of Advance Rate on Entrapment Risk of a Double-Shielded TBM in Squeezing Ground. Rock Mechanics and Rock Engineering 48(3): 1115-1130

ITASCA (2011) Fast Lagrangian analysis of continua (FLAC3D), Minnesota: Itasca Consulting Group, Inc

Kazakidis VN, Diederichs MS (1993) Tehnical Note: Understanding Jointed Rock Mass Behavior Using a Ubiquitous Joint Approach. International Journal of Rock Mechanics and Mining Science 163-172

Levy M, Courtecuisse G, Barral JP (1981). Les travaux du tunnel routier du Fréjus. Annales de l'ITBTP, 400 (TRAV PUBLICS-19) (in French)

Li G, Li H, Kato H, Mizuta Y (2003) Application of ubiquitous joint model in numerical modeling of Hilltop Mines in Japan. Chines Journal of Rock Mechanics and Engineering 22(6):951-956

Lunardi P (1980) Application de la mecanique des roches aux tunnels autoroutiers-exemple des tunnels du Fréjus (cote d'Italie) et du Gran Sasso-1ere partie. rev fr geotech (12) (in French) 
Mezger, F., Anagnostou, G., \& Ziegler, H. J. (2013). The excavation-induced convergences in the Sedrun section of the Gotthard Base Tunnel. Tunnelling and underground space technology, 38, 447-463

Panet M (1996) Two case histories of tunnels through squeezing rocks. Rock mechanics and rock engineering 29(3):155-164

Pellet F (2009) Contact between a tunnel lining and a damage-susceptible viscoplastic medium. Comput Model Eng Sci 52(3):279-295

Plana D, López C, Cornelles J. Muñoz P. (2004) Numerical Analysis of a Tunnel in an Anisotropy Rock Mass. Envalira Tunnel (Principality of Andorra). Engineering Geology for Infrastructure Planning in Europe. Springer Berlin Heidelberg 153-161

Ramoni M, Anagnostou G (2006) On the feasibility of TBM drives in squeezing ground. Tunnelling and Underground Space Technology, 21(3):262-262

Ramoni M., Anagnostou G (2008) TBM drives in squeezing ground-Shield-Rock interaction. Building underground for the future; AFTES International Congress Monaco, Montecarlo, 163-172; Edition specifique Limonest

Ramoni M, Anagnostou G, (2010) Thrust force requirements for TBMs in squeezing ground. Tunnelling and Underground Space Technology 25(4):433-455

Russo G, Repetto L, Piraud J, Laviguerie R (2009) Back-analysis of the extreme squeezing conditions in the exploratory adit to the Lyon-Turin base tunnel, (May) 9-14

Sharifzadeh M, Tarifard A., Moridi, MA (2013) Time-dependent behavior of tunnel lining in weak rock mass based on displacement back analysis method. Tunnelling and Underground Space Technology, 38:348-356

SITAF (1982) Traforo autostradale del Fréjus (in Italian)

Steiner W (1996). Tunnelling in squeezing rocks: case histories. Rock Mechanics and Rock Engineering, 29(4):211-246

Sulem J, Panet M., Guenot A (1987).Closure Analysis in Deep Tunnels. International journal of rock mechanics and mining sciences \& geomechanics abstracts 24(3): 145-154

Sulem J. (2013) Tunnel du Fréjus: Mesures géotechniques et interprétation, Manuel de Mécanique des Roches Tome IV, chap. 7, Presse des Mines

Tran-Manh H, Sulem J, Subrin D, \& Billaux D (2015) Anisotropic Time-Dependent Modeling of Tunnel Excavation in Squeezing Ground. Rock Mechanics and Rock Engineering 48(6):2301-2317

Vinnac A (2012) Rétro-analyse du creusement au tunnelier de la galerie de sécurité du tunnel routier du Fréjus. Mémoire de mastère spécialisé 'Tunnels et Ouvrages souterrains', ENTPE (in French)

Wang TT, Huang TH (2009) A constitutive model for the deformation of a rock mass containing sets of ubiquitous joints. International Journal of Rock Mechanics and Mining Sciences 46(3):521-530

Wang TT, Huang TH (2013) Anisotropic Deformation of a Circular Tunnel Excavated in a Rock Mass Containing Sets of Ubiquitous Joints: Theory Analysis and Numerical Modeling. Rock Mechanics and Rock Engineering 47(2):643-657 


\begin{tabular}{|c|c|c|c|c|c|}
\hline Section & Chainage & $\alpha$ & $c_{\mathrm{j}}$ & $C_{\infty \times 1-4}$ & $\beta$ \\
\hline 8 & 1905 & 0.97 & 0.28 & 18.2 & 2.24 \\
\hline 11 & 1965 & 0.95 & 0.24 & 20.72 & 2,22 \\
\hline 12 & 1976 & 1.00 & 0.15 & 23.28 & 2,51 \\
\hline 13 & 1998 & 0.85 & 0.30 & 20.38 & 1,73 \\
\hline 14 & 2018 & 0.70 & 0.33 & 14.75 & 1,83 \\
\hline 16 & 2063 & 0.75 & 0.00 & 13.64 & 3,85 \\
\hline 18 & 2136 & 0.60 & 0.00 & 10.66 & 3,84 \\
\hline 19 & 2157 & \multicolumn{2}{|c|}{ Anisotropy ratio $>4$} & 7.18 & 6.42 \\
\hline 20 & 2184,5 & \multicolumn{2}{|c|}{ Anisotropy ratio $>4$} & 11.28 & 4.29 \\
\hline 23 & 2267 & 0.60 & 0.20 & 11.01 & 2,37 \\
\hline 24 & 2287 & 0.20 & 0.07 & 6.98 & 2,60 \\
\hline 25 & 2289 & 0.50 & 0.28 & 8.93 & 2,12 \\
\hline 26 & 2292,5 & 0.30 & 0.35 & 7.60 & 1,92 \\
\hline 28 & 2296 & 0.45 & 0.52 & 8.11 & 1,74 \\
\hline 29 & 2322 & 0.00 & 0.15 & 6.34 & 1,89 \\
\hline 30 & 2341 & 0.45 & 0.00 & 8.88 & 3,41 \\
\hline 33 & 2438 & 0.70 & 1.40 & 9.72 & 1,29 \\
\hline 36 & 2509 & 0.77 & 0.15 & 13.05 & 2,81 \\
\hline 37 & 2531 & 0.70 & 0.00 & 11.84 & 3,83 \\
\hline 41 & 2626 & 0.70 & 0.15 & 11.60 & 2,57 \\
\hline 43 & 2682 & 0.65 & 0.09 & 10.91 & 3,12 \\
\hline 44 & 2723 & 0.70 & 0.15 & 11.30 & 2,73 \\
\hline 45 & 2745 & \multicolumn{2}{|c|}{ Anisotropy $>4$} & 8.03 & 4.65 \\
\hline
\end{tabular}

Tab1. Fitted values of $\alpha$ and $c_{\mathrm{j}}$ for each section within zone A 
1

2

3

4

5

6

8

9

10

11

12

13

14

15

16

17

18

19

20

21

22

23

24

25

26

27

28

29

30

31

32

33

34

35

36

37

38

39

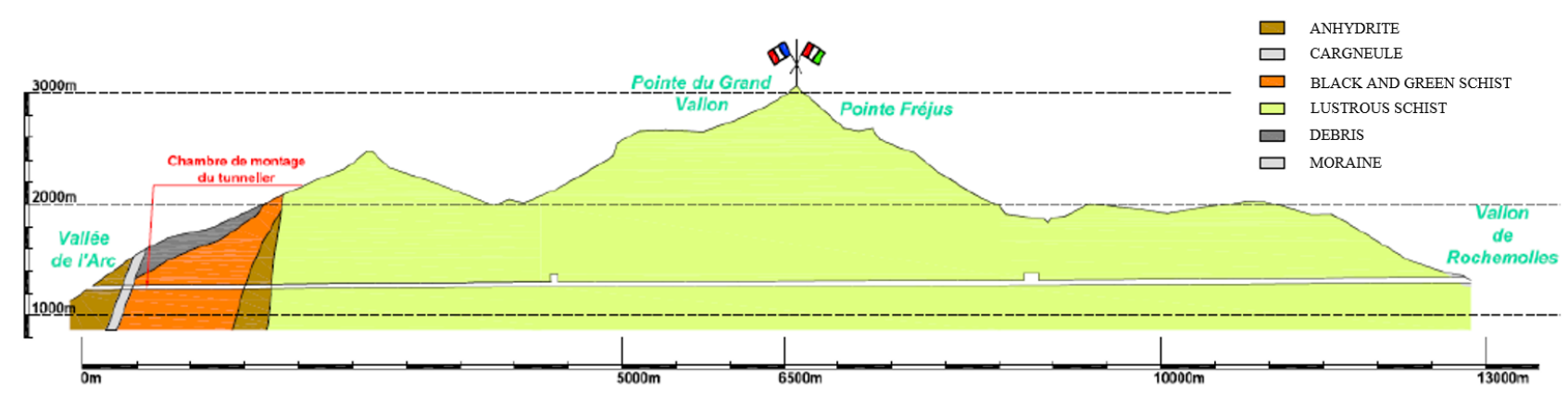

Fig1. Geological profile of the alignment

(1)

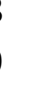

20

2




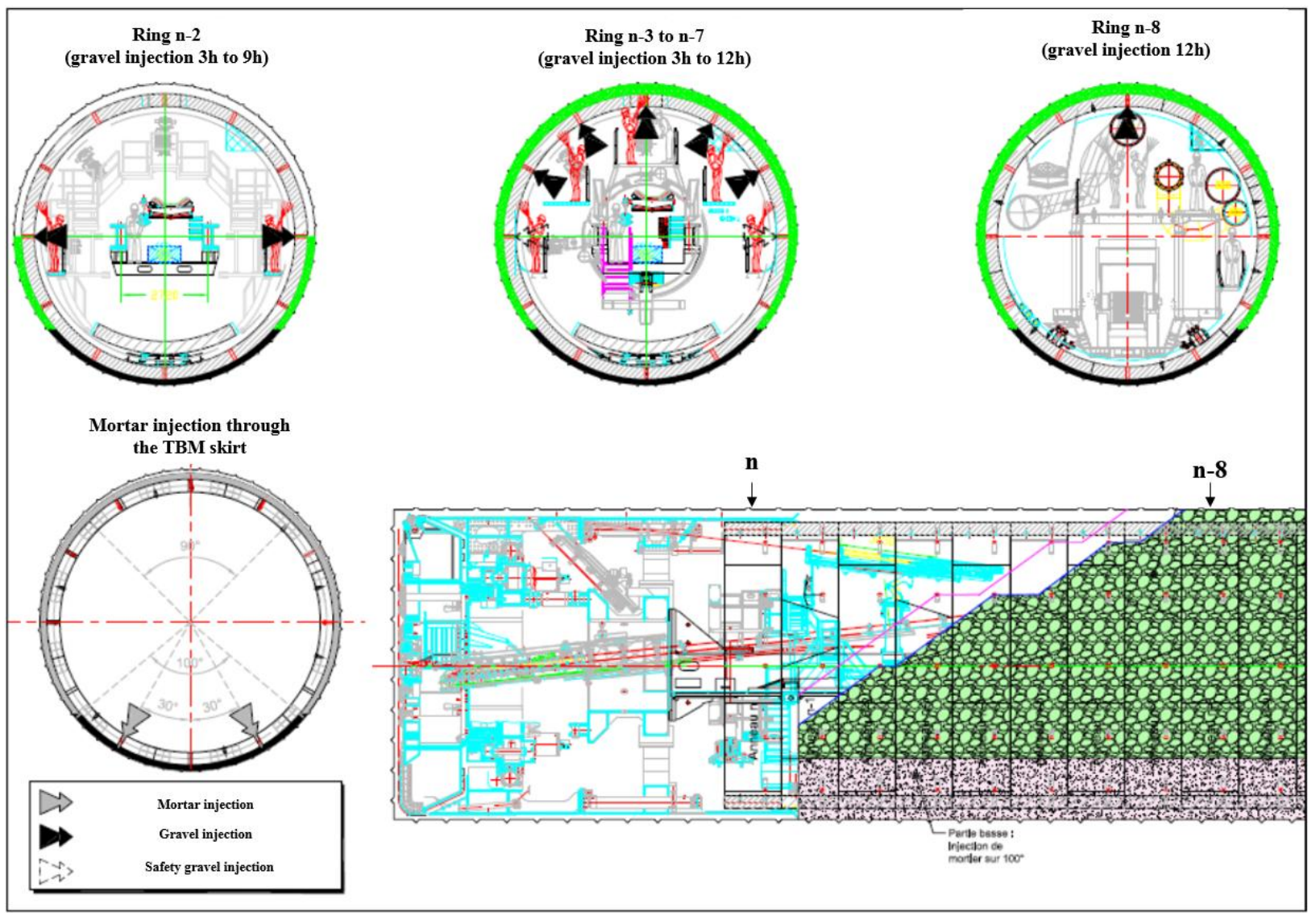

Fig2. Backfilling technique of the annular gap after Vinnac (2012) 

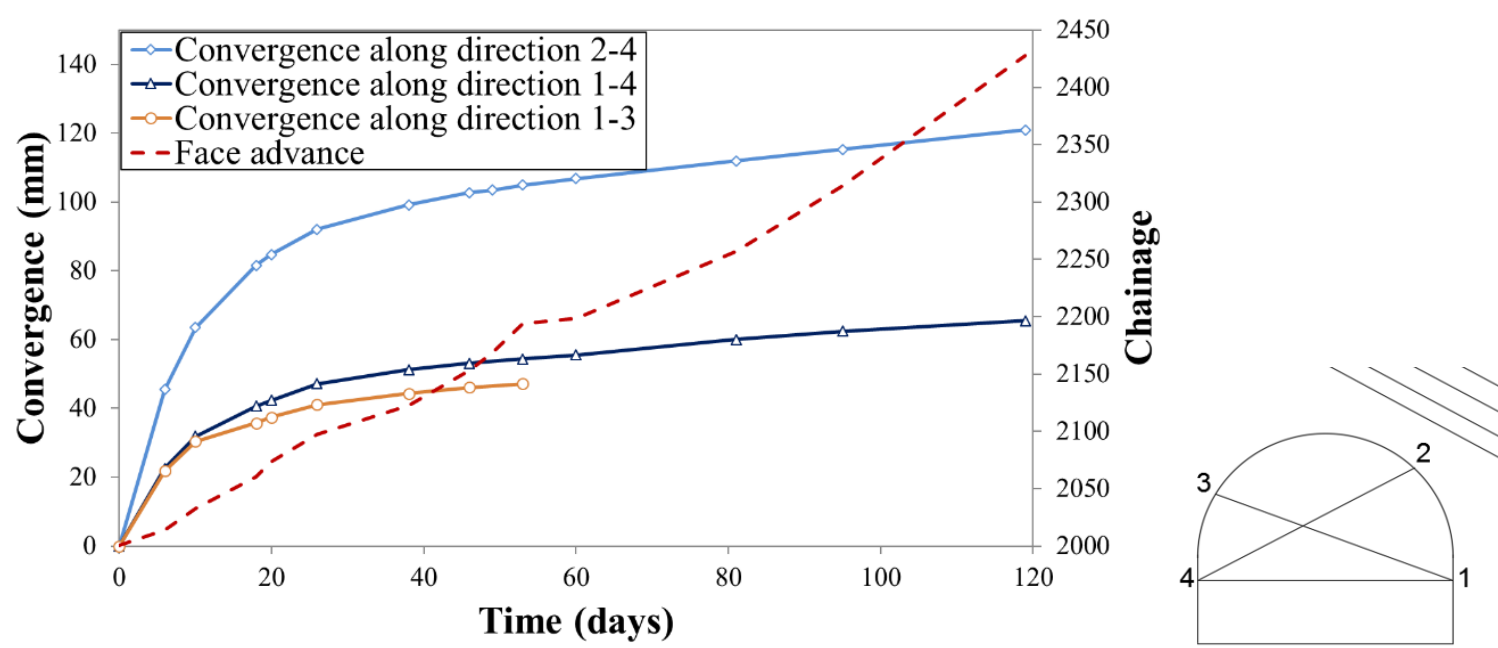

Fig3. Convergence curves and schematic position of the targets in section 13 (chainage 1998) 

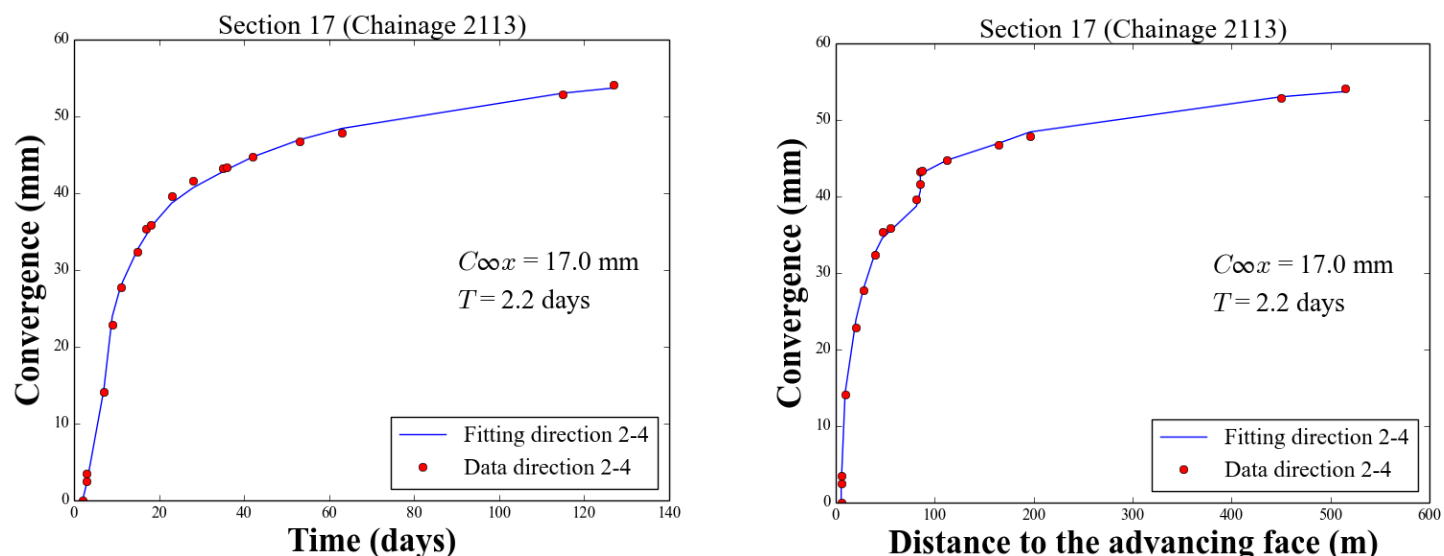

(a)

Distance to the advancing face (m)
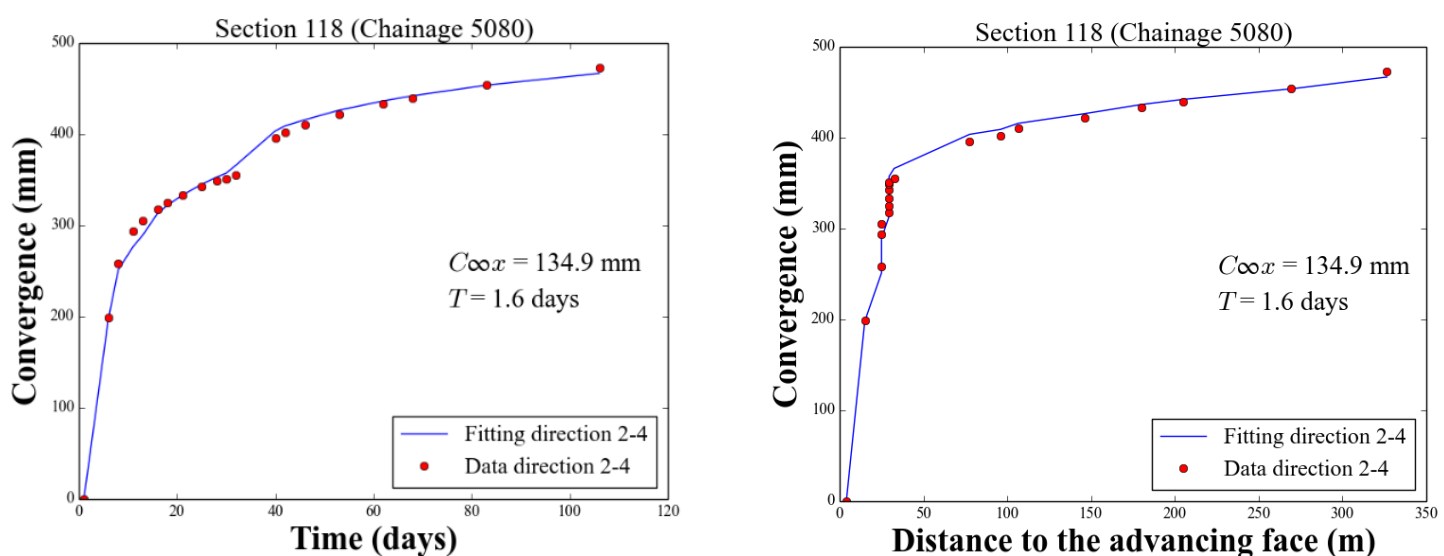

(b)

Fig4. Convergence evolution along direction 2-4 and fit with the law of de Sulem et al. (1987) for section 17 at chainage 2113 (a) and section 118 at chainage 5080 (b). On the left in function of time and on the right in function of the distance to the advancing face 


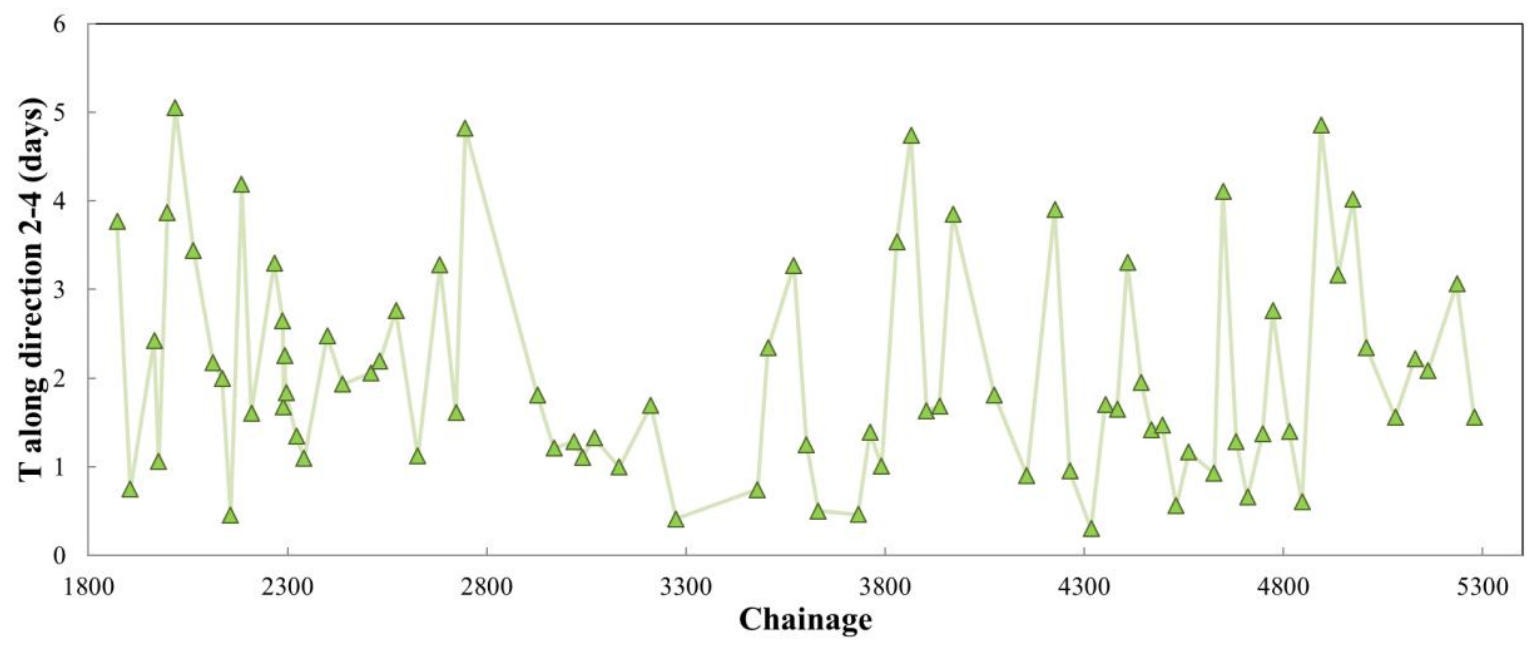

Fig5. Evolution of $T$ along direction 2-4 along the road tunnel after De la Fuente et al., (2017) 


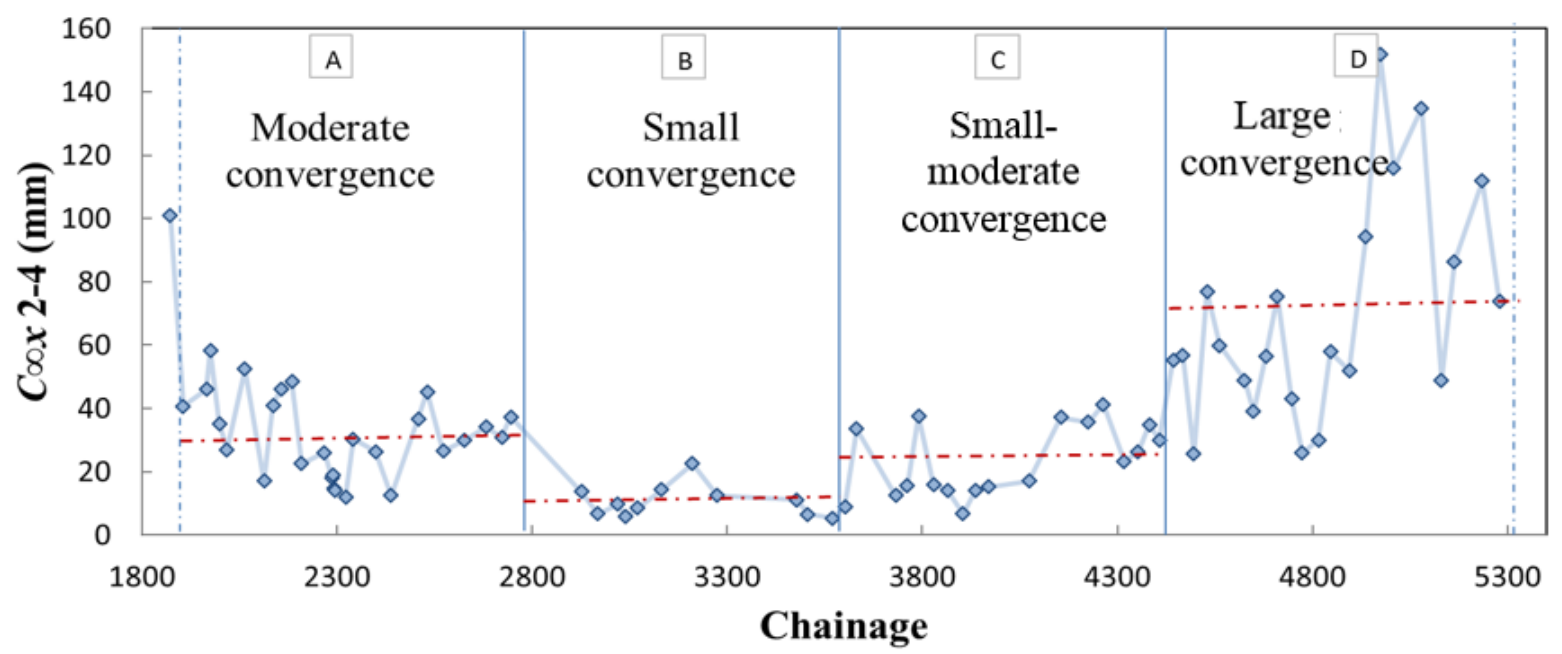

(a)

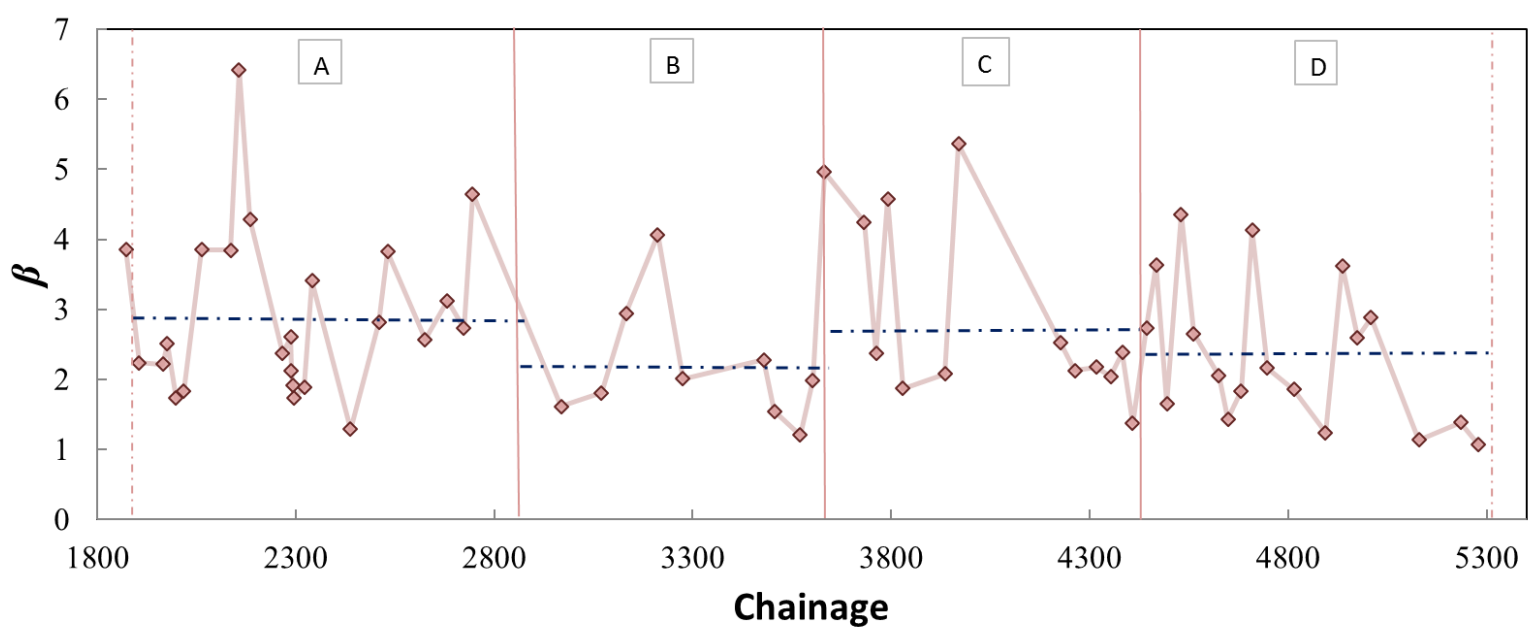

(b)

Fig6. Evolution of $C_{\infty x}$ along direction 2-4 along the road tunnel (the red dotted lines represent the average convergence value for each zone) (a). Evolution of $\beta$ along the road tunnel (the blue dotted lines represent the average convergence value for each zone) (b). After De la Fuente et al., (2017) 

1

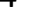

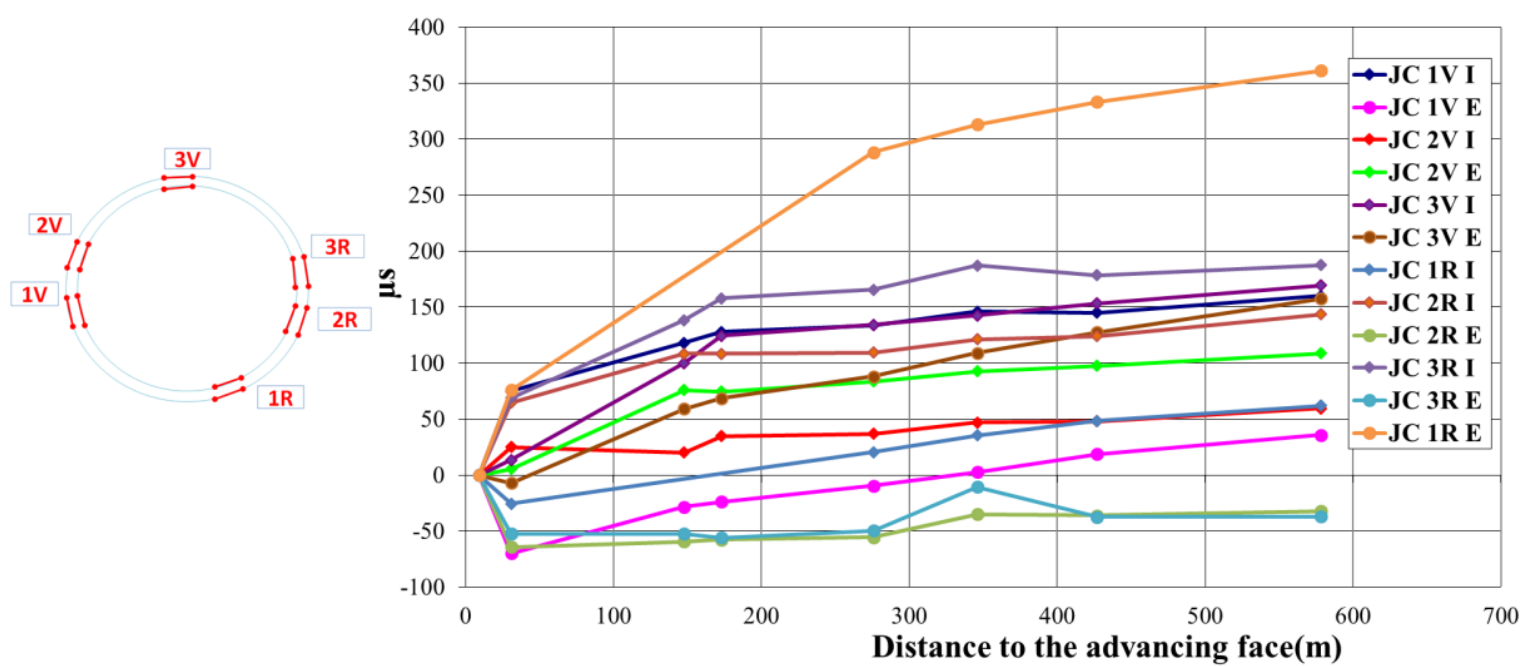

Fig7. Distribution of the strain gauges in the ring 1821, Chainage 3917 (raw data) (1)

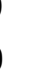

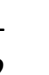
33 


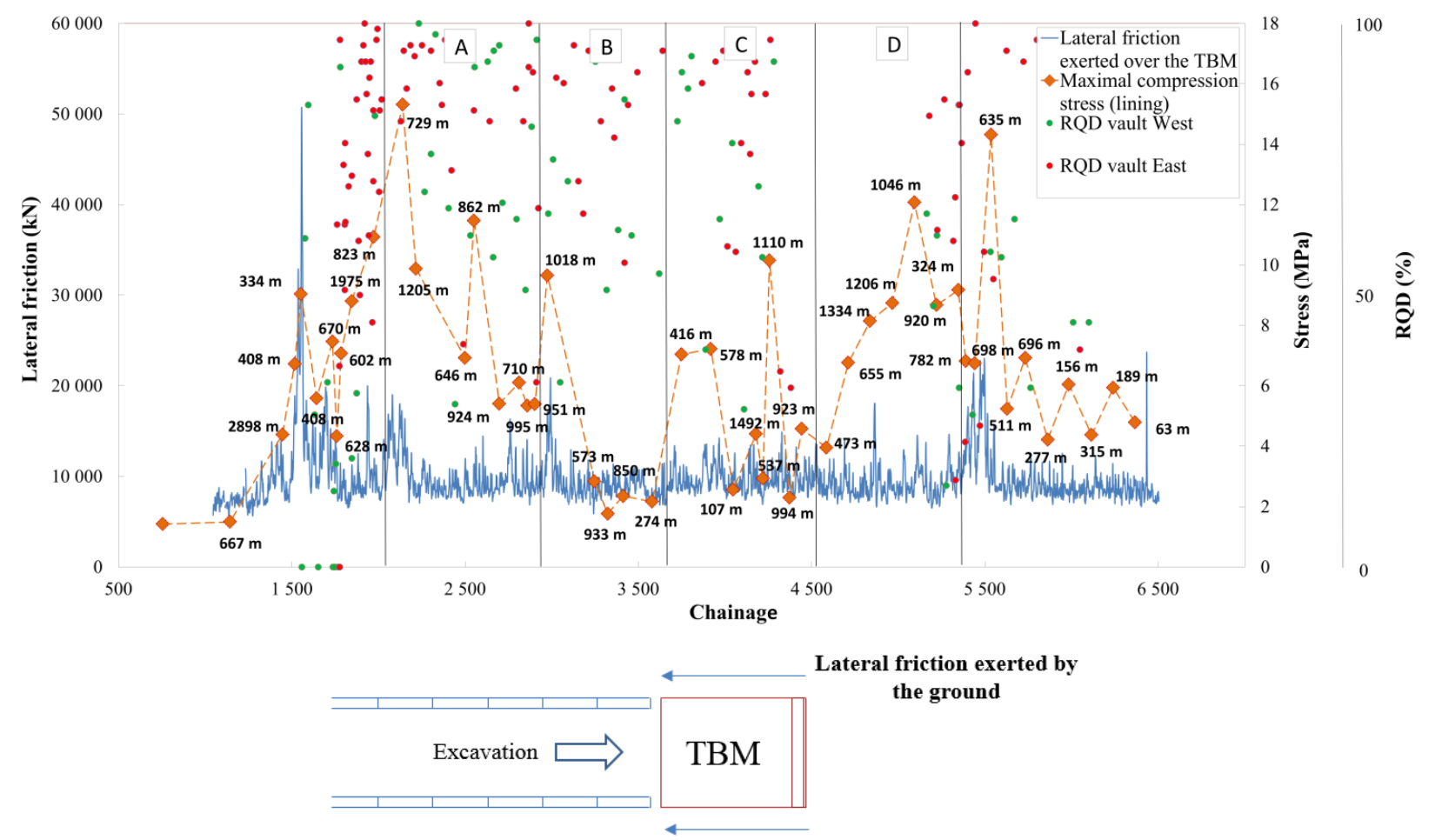

Fig8. Lateral friction exerted by the ground over the TBM skirt, maximal compression stress measured in the lining (the distance to the excavation face at which the stress has been retrieved can be found next to each point representing the stress state) and RQD values of the ground retrieved from the East or the West side of the vault during the excavation, as a function of chainage in the safety gallery (De la Fuente et al., 2017) 

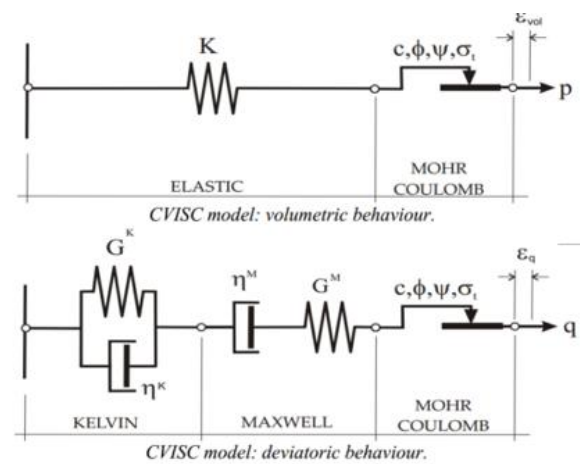

CVISC Model

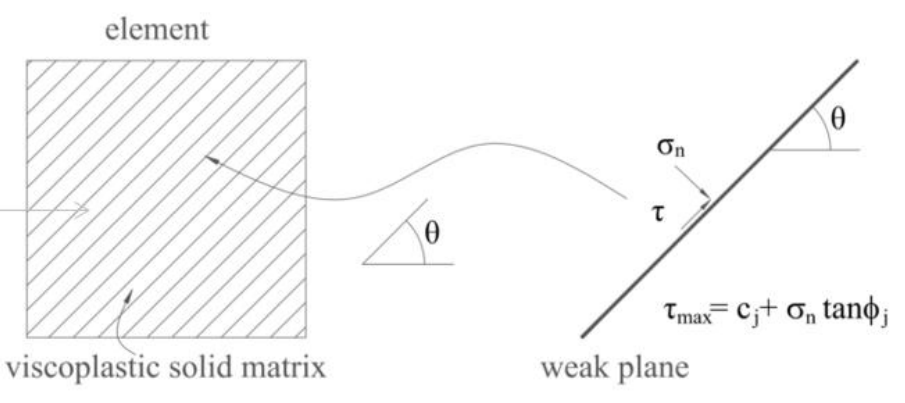

Ubiquitous joints model

Fig9. Ubiquitous joint model in a viscoplastic matrix 
13

14

15

16

17 9 3

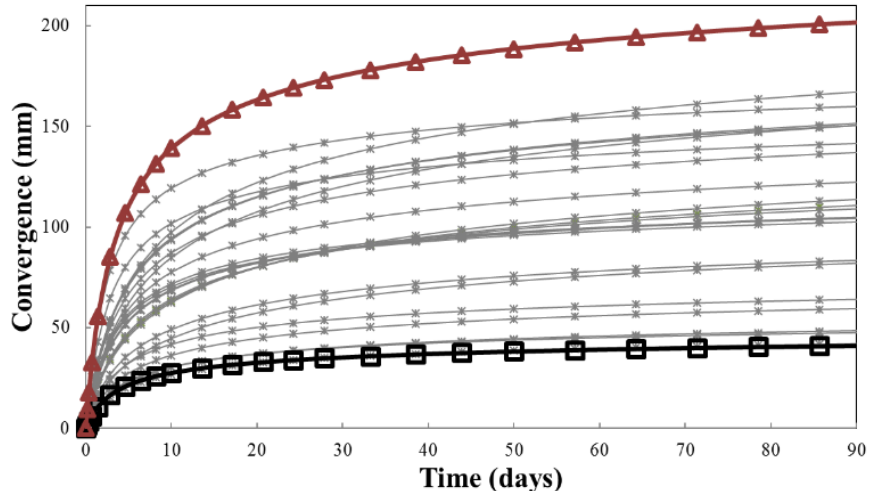

(a)

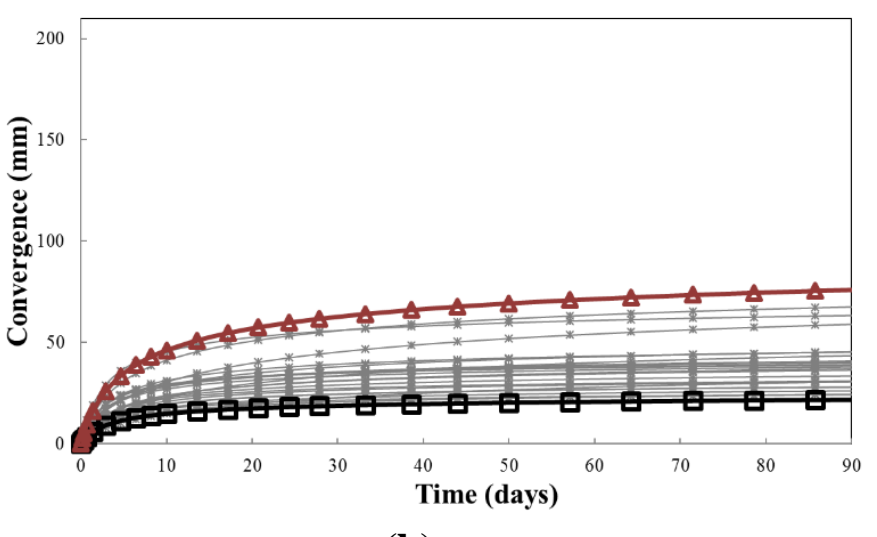

(b)

-Section 12 (chainage 1976)

Đ-Section 29 (chainage 2322)

$\rightarrow$-Other sections within zone A

Fig10. Convergence curves in the "homogeneous zone A" along direction 2-4 (a) and along direction 1-4 (b)

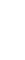
6 18 40 1 4 


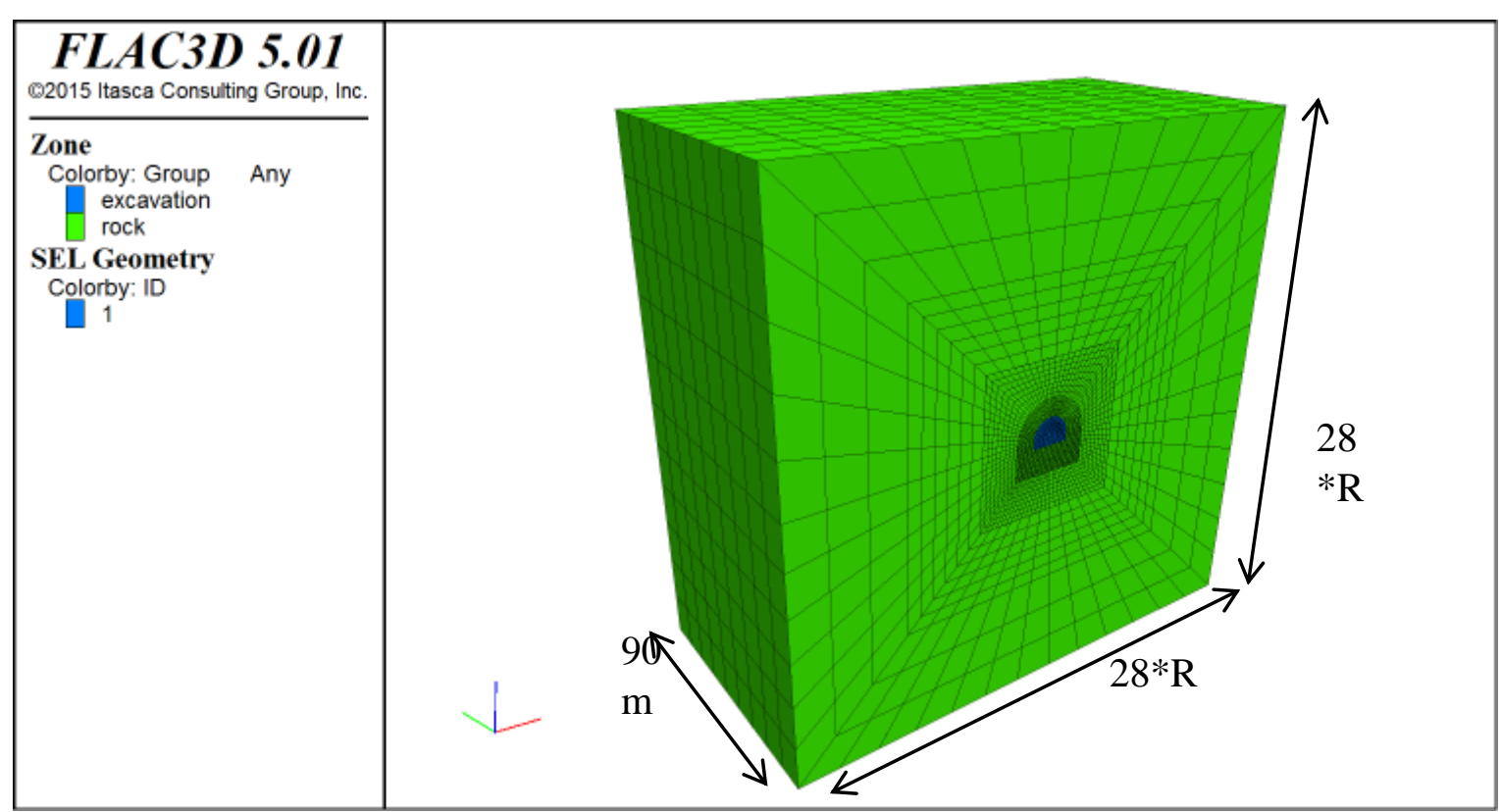

(a)

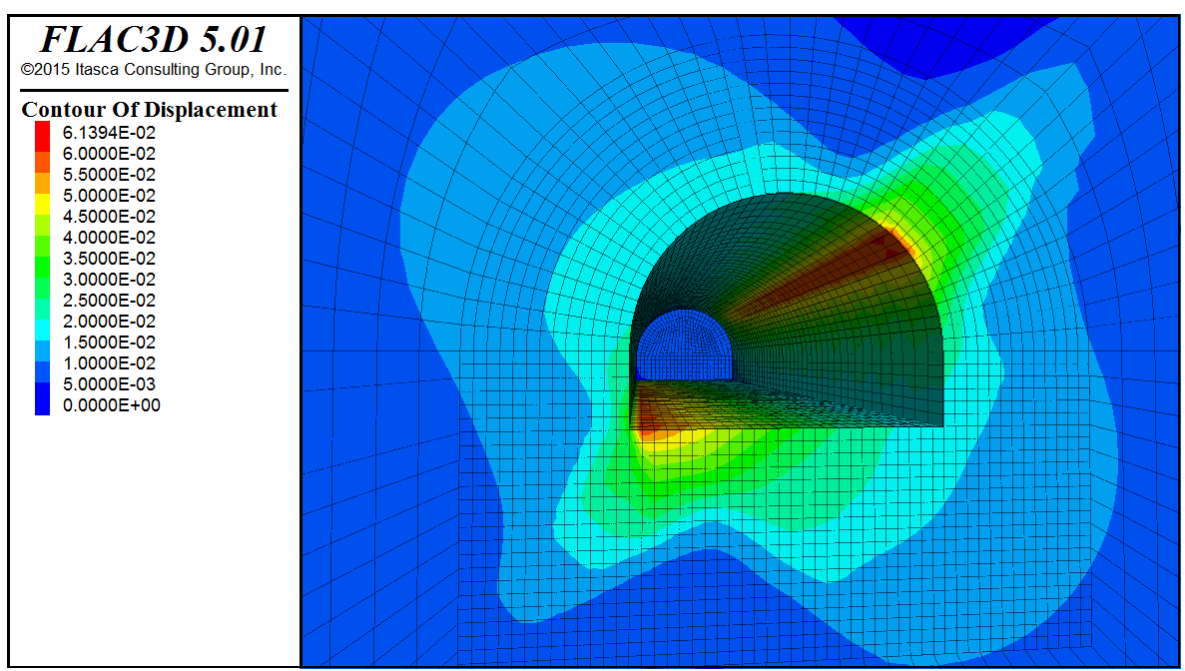


(b)

Fig11. Geometry of the model (a). Detail of the displacements around the tunnel during its excavation for section 12 (chainage 1976) (b). $\mathrm{R}$ is the radius of the vault of the excavated tunnel $(5.8 \mathrm{~m})$

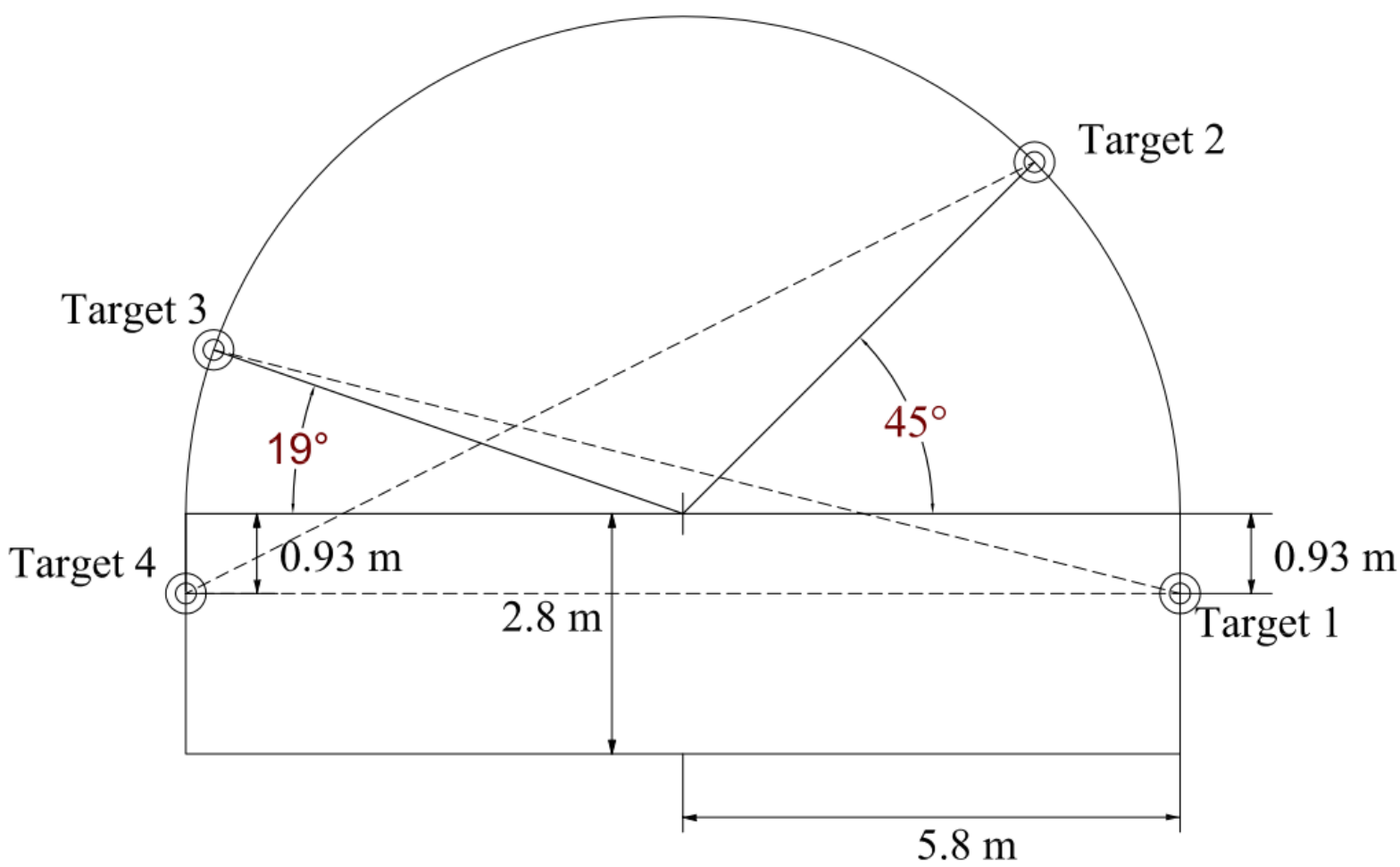

Fig12. Geometry of the tunnel and average position of the targets considered in the simulations 
Section 12 (chainage 1976)

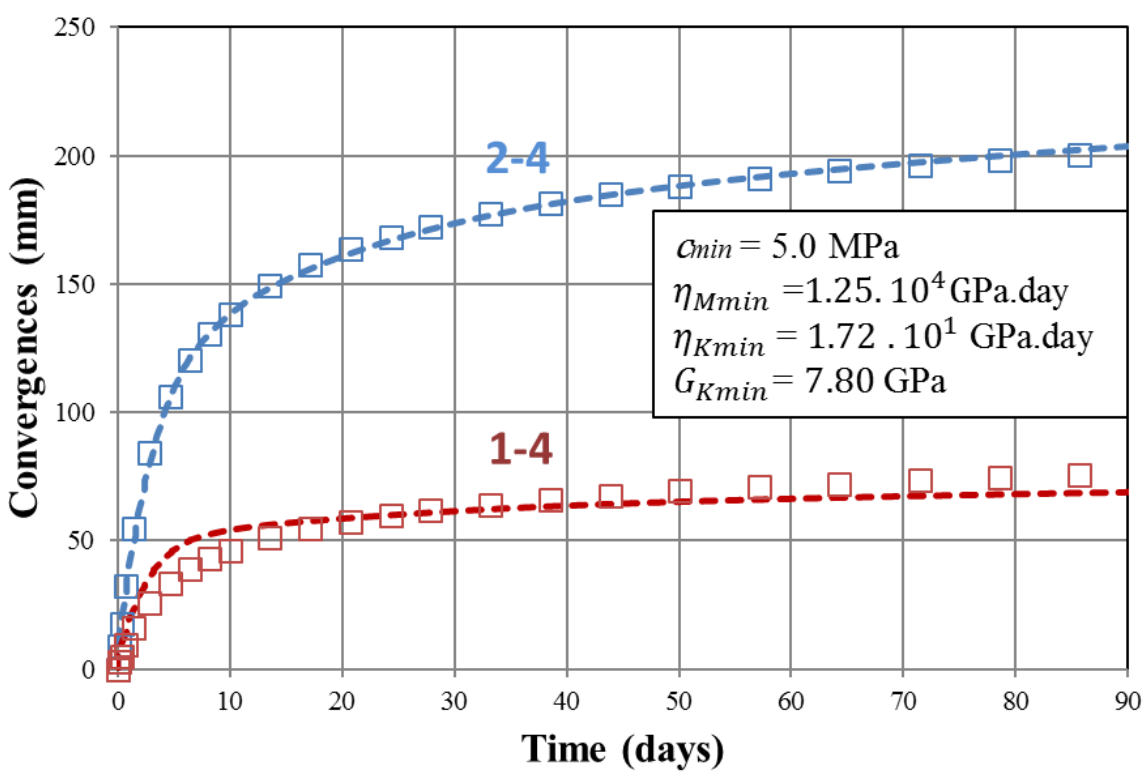

(a)

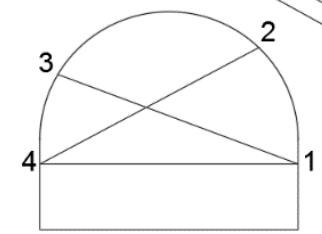

Section 29 (chainage 2322) 


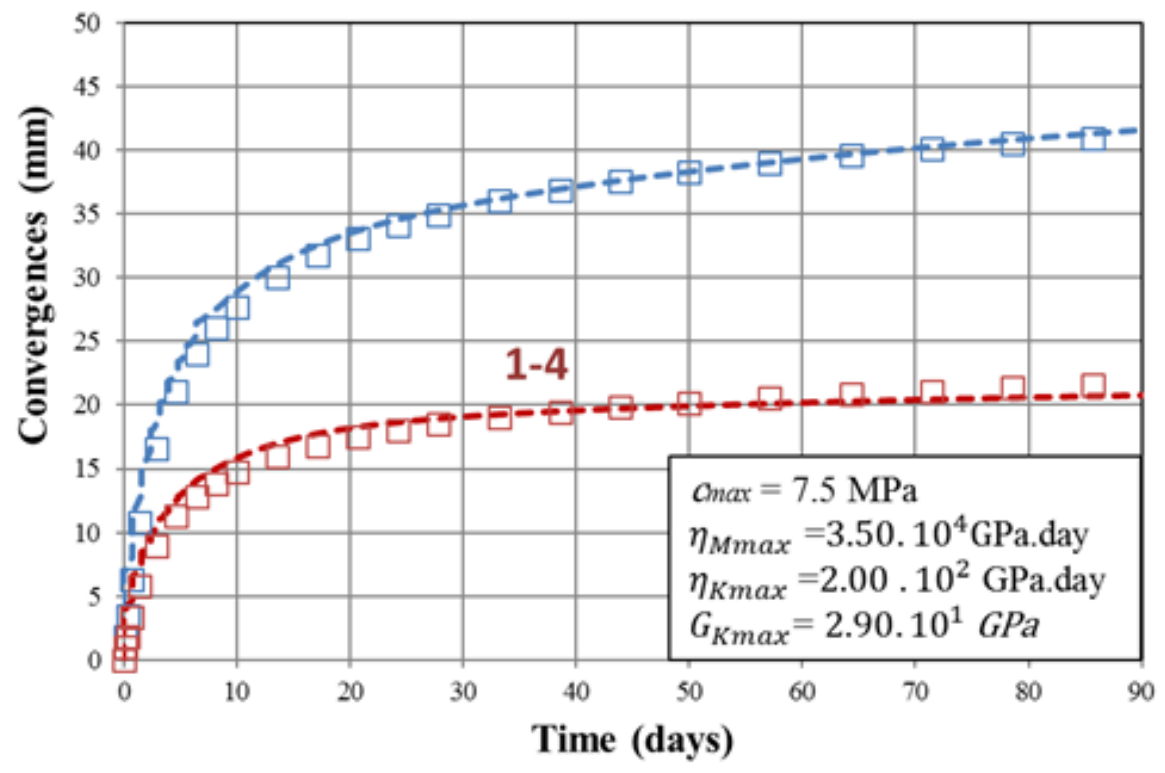

(b)

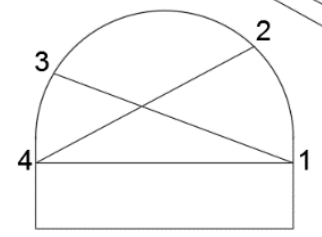

Fig13. Back analysis of convergence data of section 29 (chainage 2322) ( smallest convergence) and schematic average distribution of the targets (right) in the section (a) back analysis of convergence data of section 12 (chainage 1976) (largest convergence) and schematic average position of the targets (right) in the section (b)

9

10

11
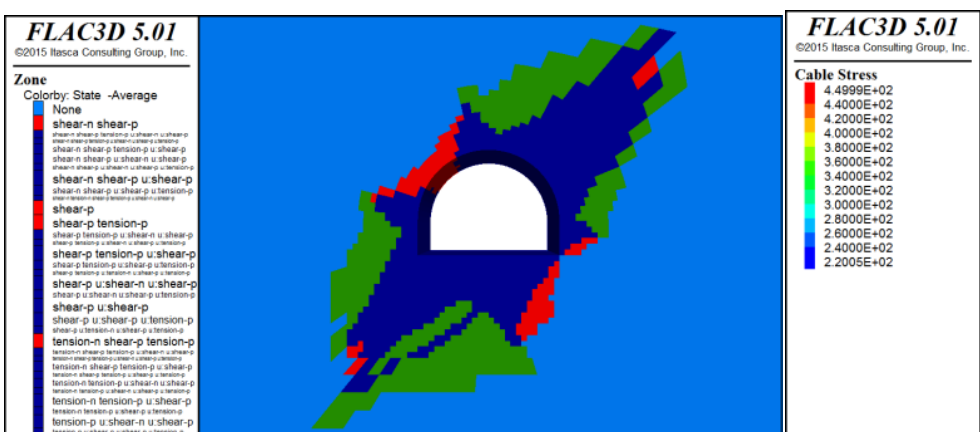

(a)
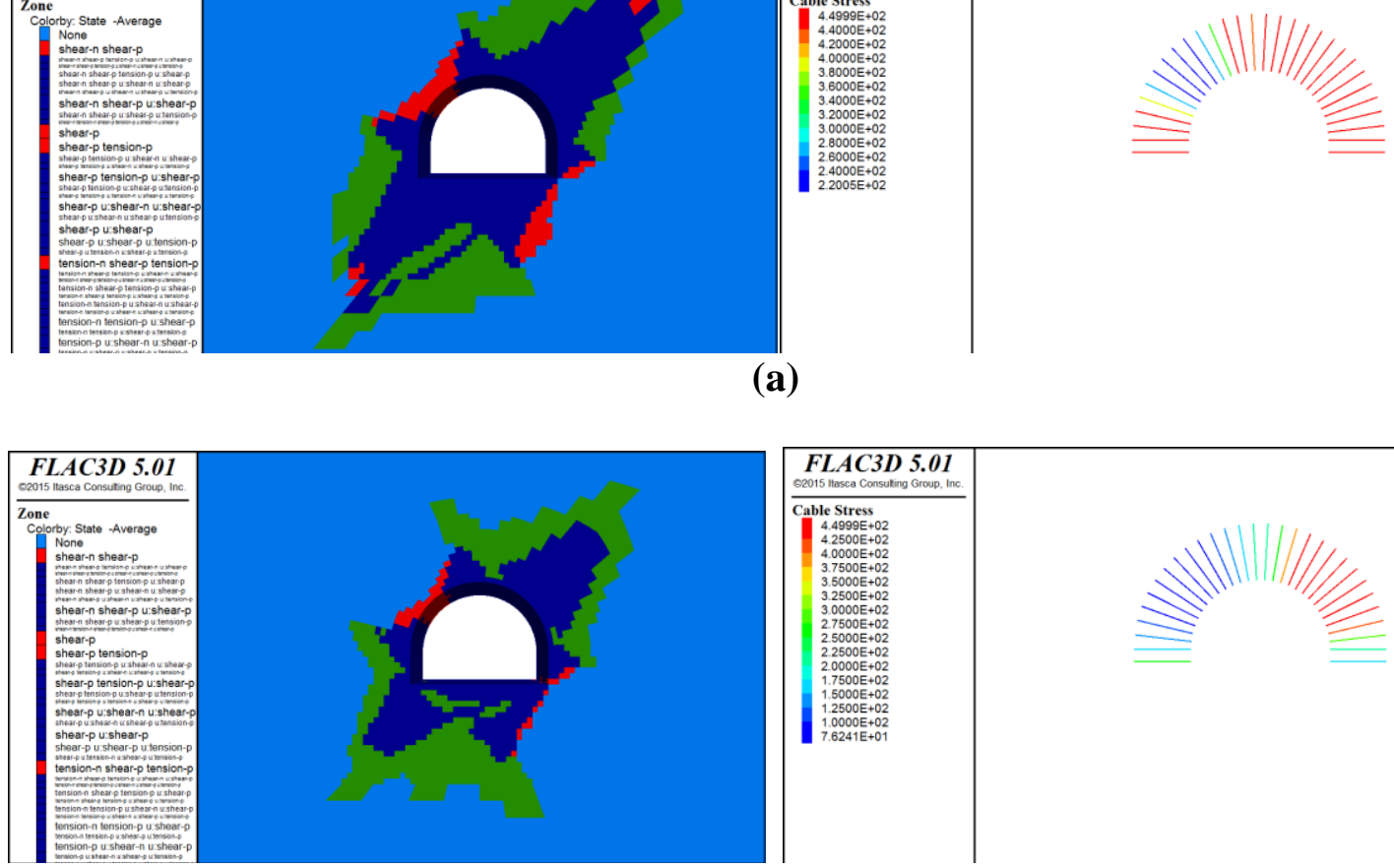

(b) 
1 Fig14. Plastic areas around the tunnel excavation and stress state in the rockbolts in section 12 2 (chainage 1976) (largest convergence) (a) and plastic areas around the tunnel excavation and 3 stress state in the rockbolts in section 29 (chainage 2322) (smallest convergence) (b) .

4 Red zones are the areas where the matrix is in plastic state, green zones are the areas where 5 joints are in plastic state and blue zones are the areas where matrix and joints are in plastic 6 state at the same time. Rockbolts drawn in red have reached the elastic limit.

8

9

10

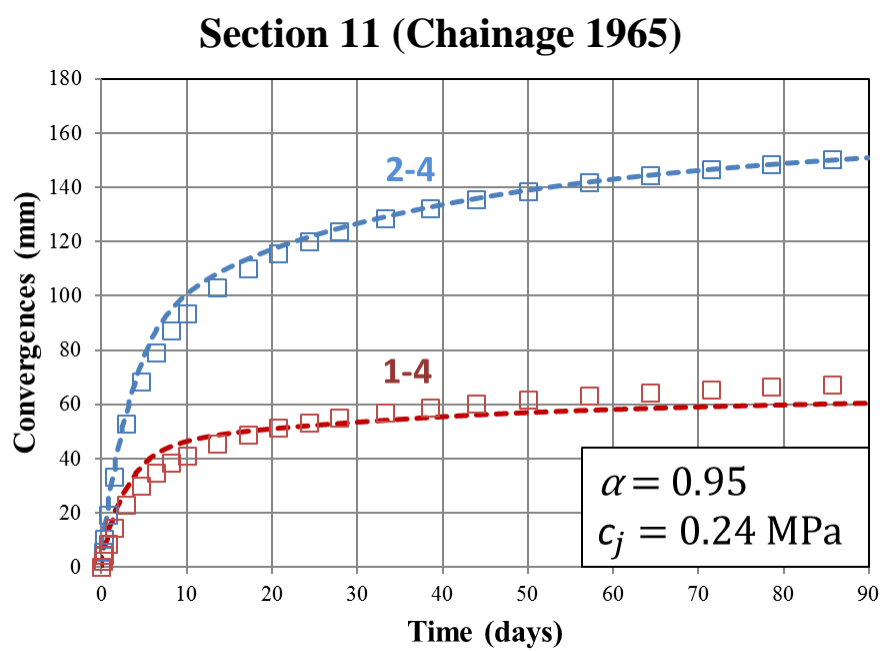

Section 23 (Chainage 2267) 
1

2

3

4
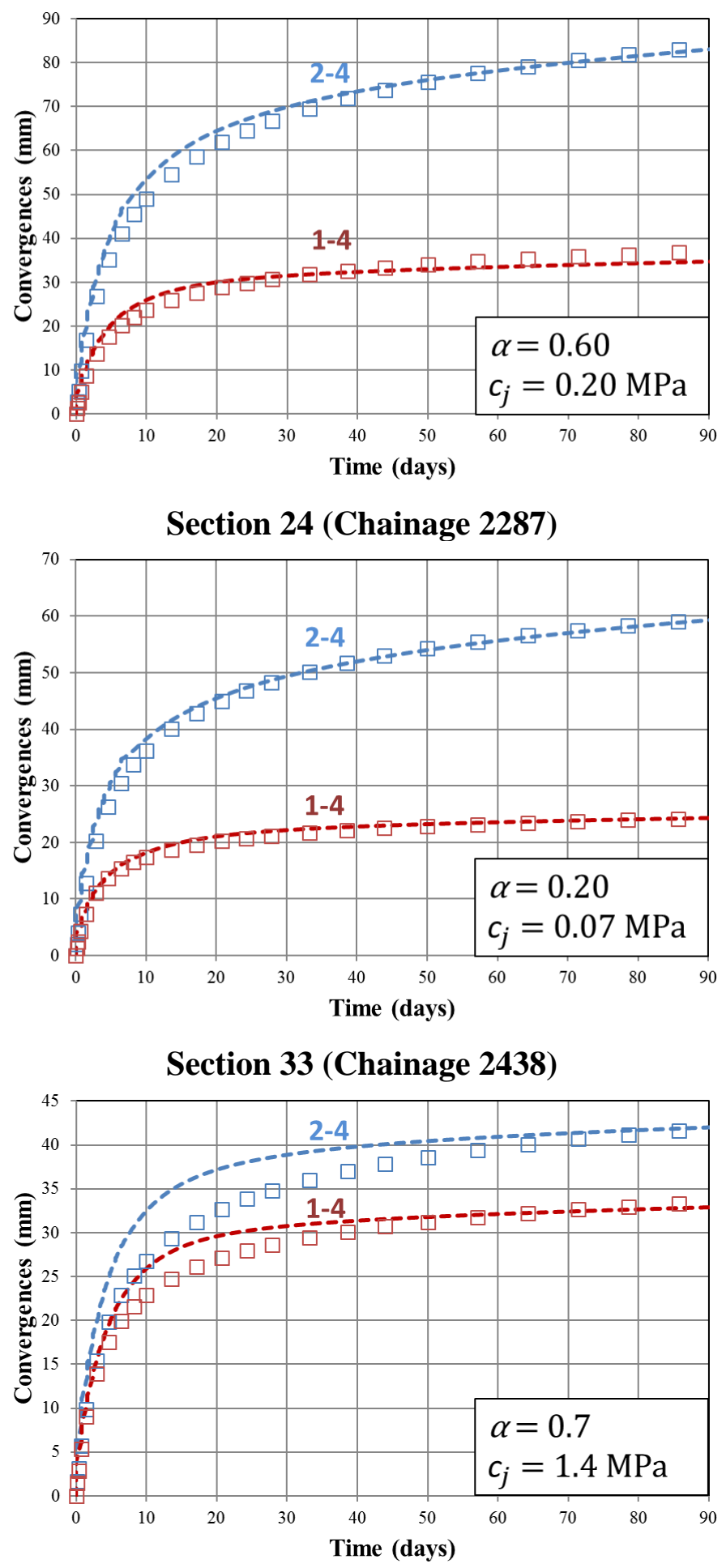

Fig15. Back analysis of convergence data of sections within zone A (from chainage 1905 to chainage 2723) 
1

2

3

4

5

6

7

8

9

10

11

12

13

14

15

16

17

18

19

20

21

22

23

24

25

26

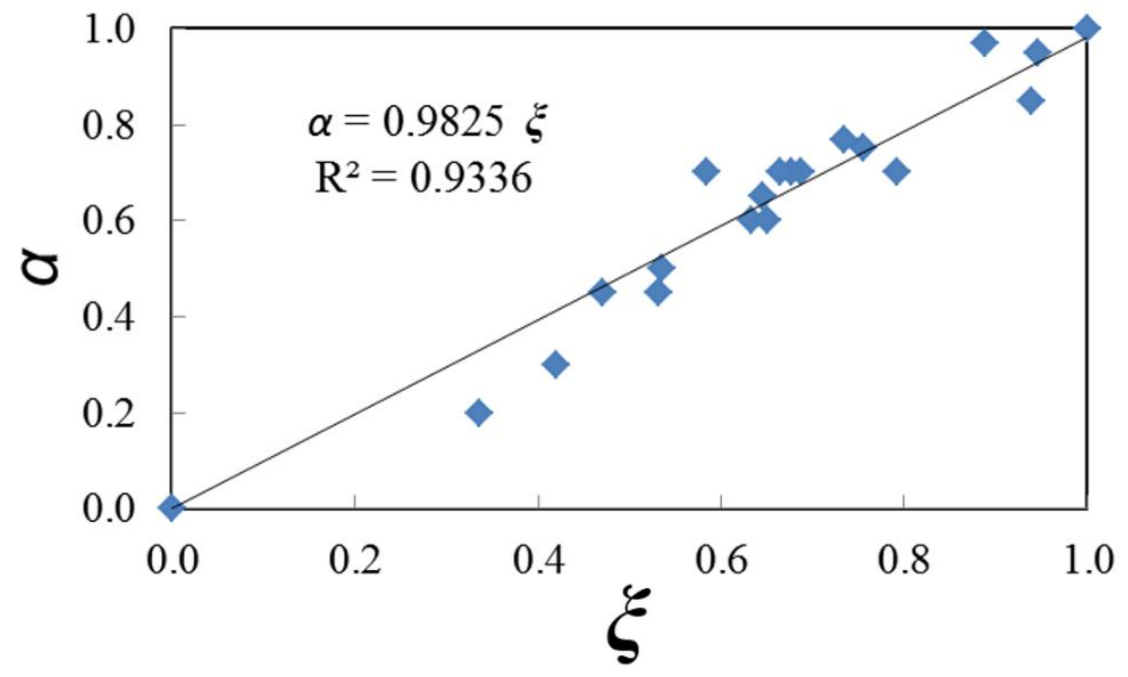

Fig16. Linear correlation between $\alpha$ and $\xi$ 
1

2

3

4

5

6

8

9

10

11

12

13

14

15

16

17

18

19

20

21

22

23

24

25

26

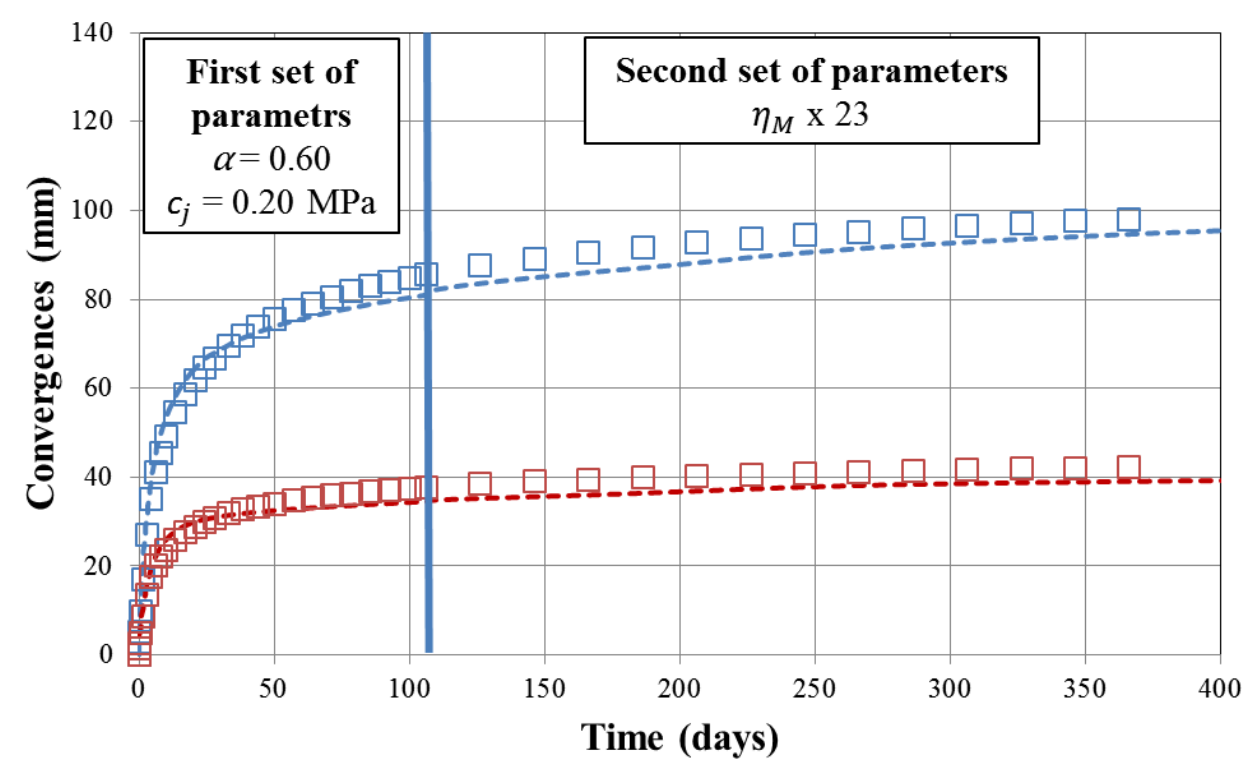

(a) 


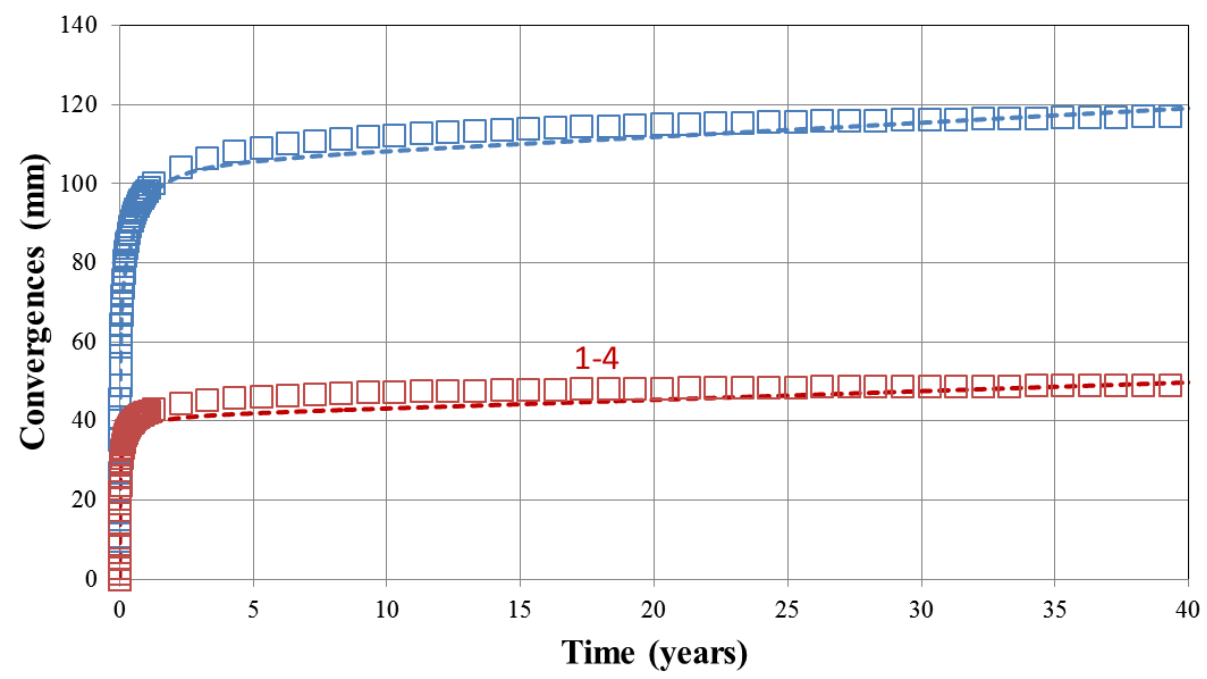

(b)

Fig17. Medium-term (a) and long-term (b) back analysis of convergence data of section 23 within zone A (chainage 2267)

5

6

7

8

9

10

11

12

13

14

15

16

17

18

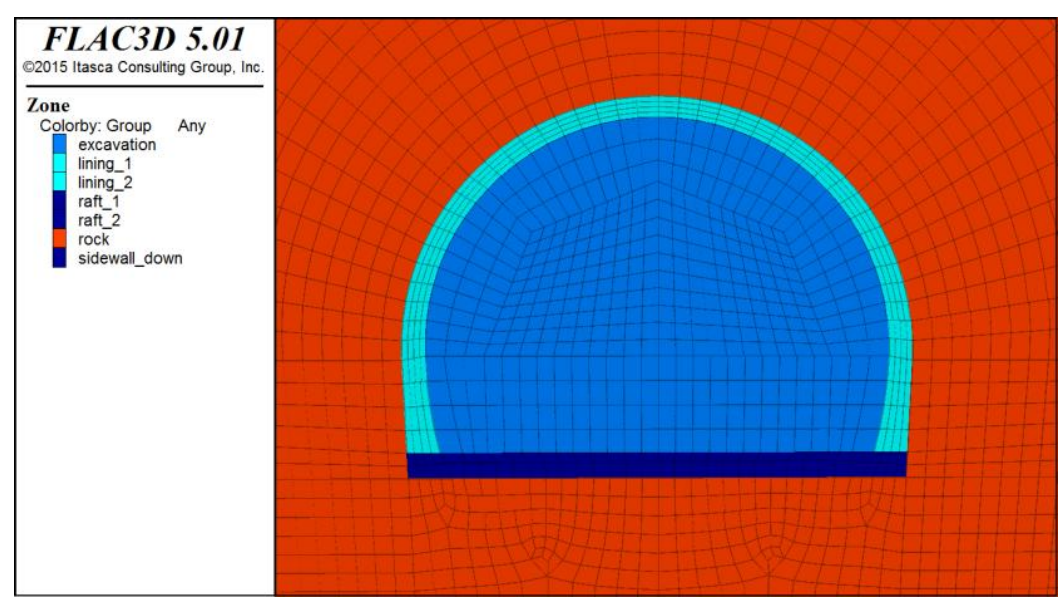

Fig18. Geometry of the model: the Fréjus road tunnel and its final lining 
24

25

26

27

28

29

30

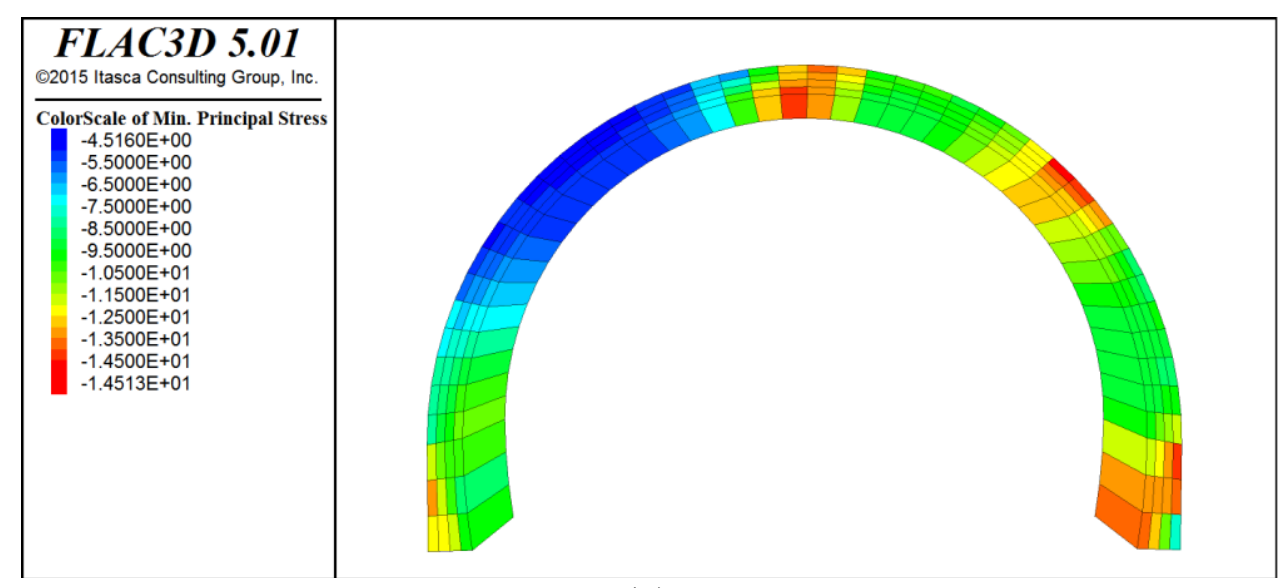

(a) 


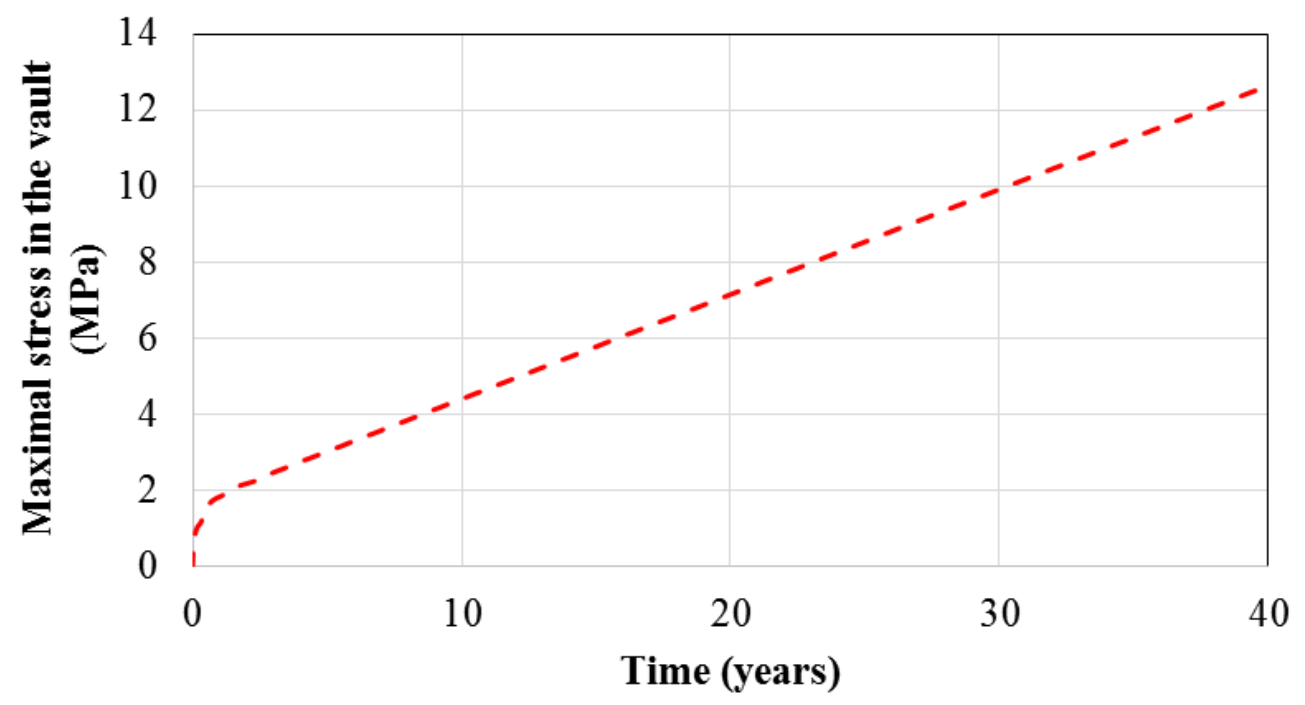

1 2 3 4 5 6 7 8 9 10 11 12 13 14 15 16 17 18 19 20 21

(b)

Fig19. Plot of the computed maximal principal stress in the vault of the road tunnel after 40 years (a). Computed stress in the West side of the vault as a function of time (b) 


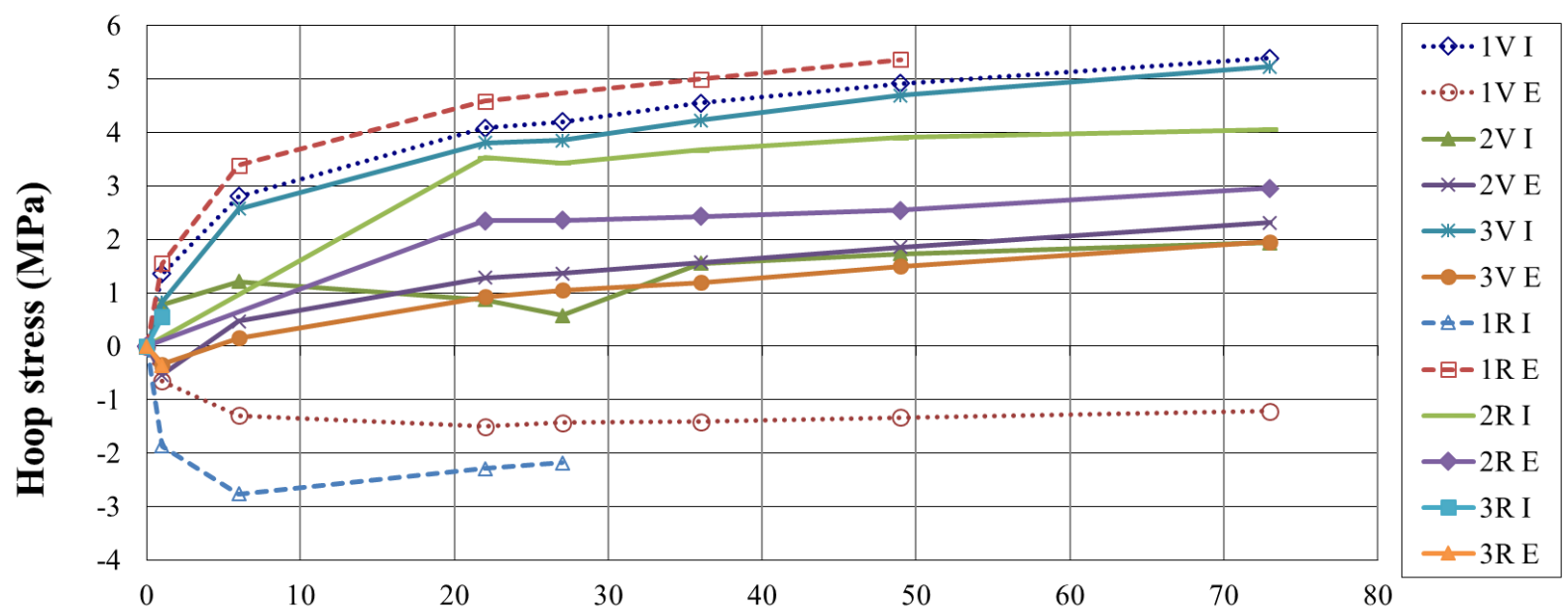

1 2

Time (days)

(a)

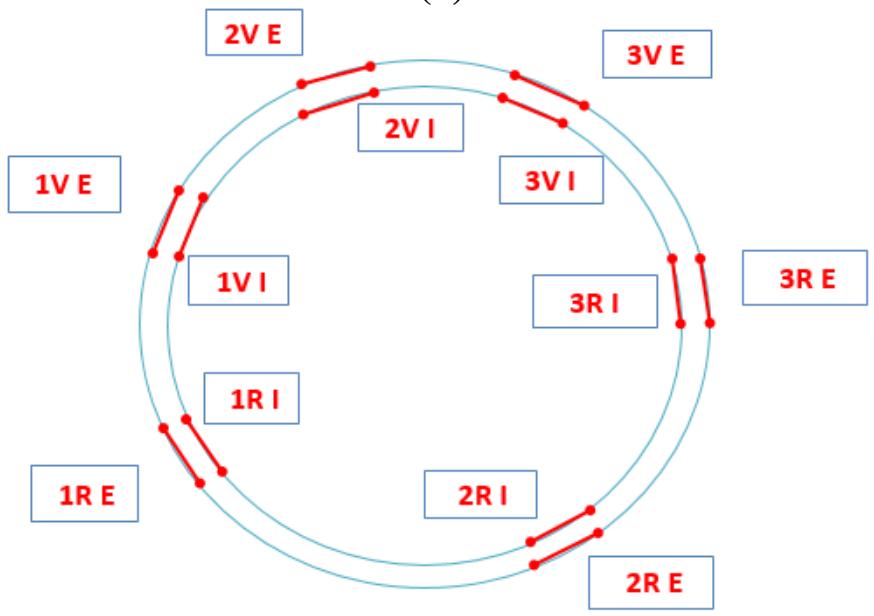

(b)

Fig20. Evolution of the stress state in function of time in section 1257 (chainage 2902) (a) schematic representation of the position of the strain gauges within the concrete ring (b) (the evolution of the time-dependent convergence of the ground is in solid line whereas the evolution of convergence originated from instantaneous buckling is in dashed line) 


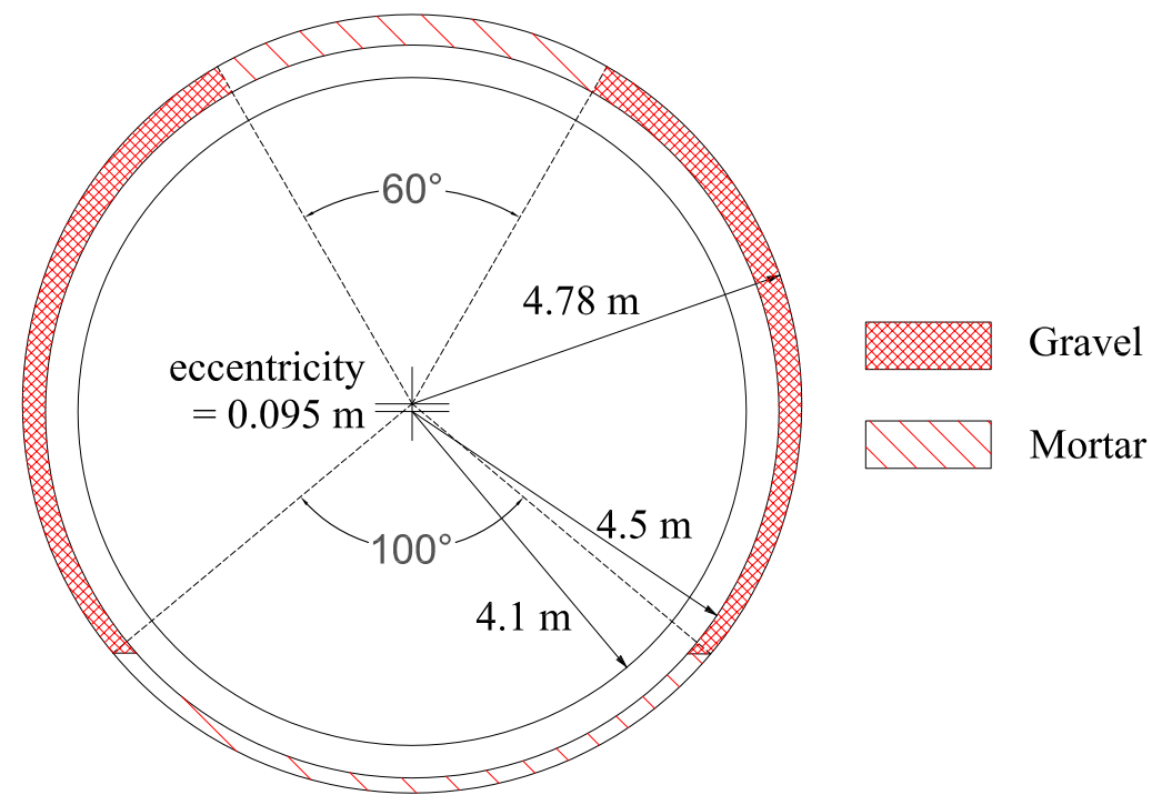

(a)

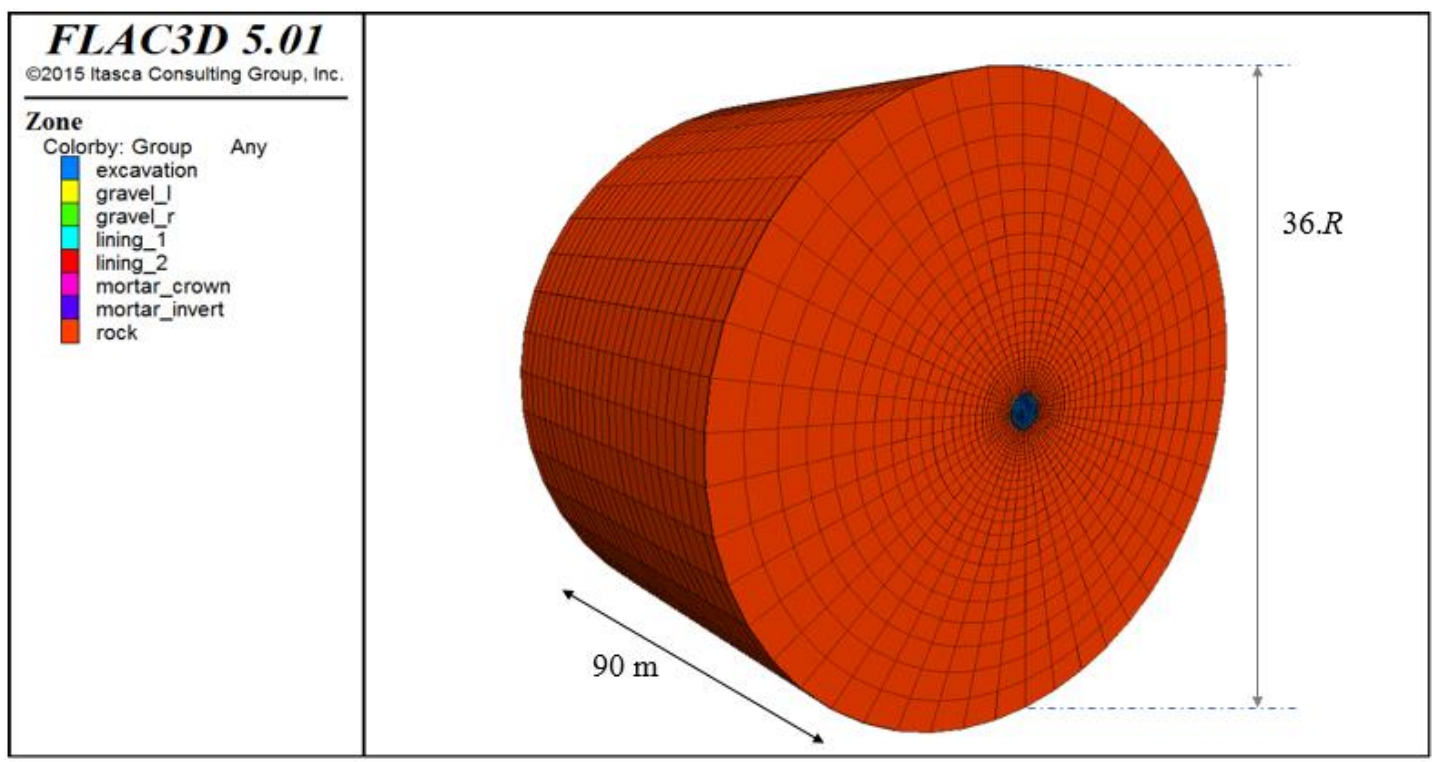

(a)

Fig21. Scheme of the geometry of the lining and the backfilling in the safety gallery (a) geometry of the numerical model of the safety gallery (b) 


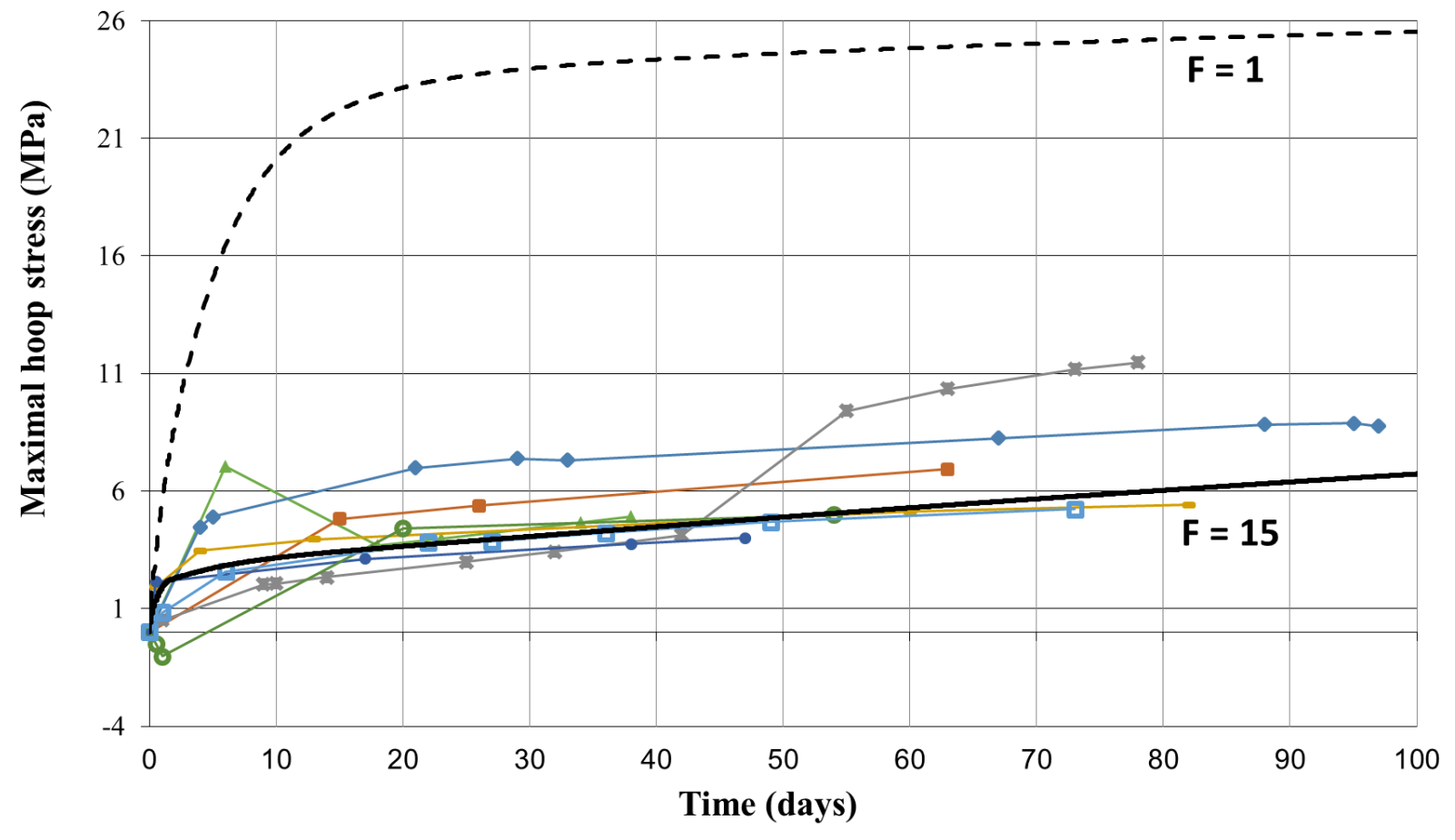

1

Fig22. Fitting of the parameter $F$ with the average maximal hoop stress obtained with the model parameters describing the average behavior of the road tunnel $\left(\alpha=0.65\right.$ and $c_{\mathrm{j}}=0.2$ $\mathrm{MPa})$

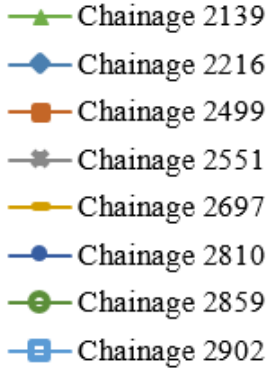



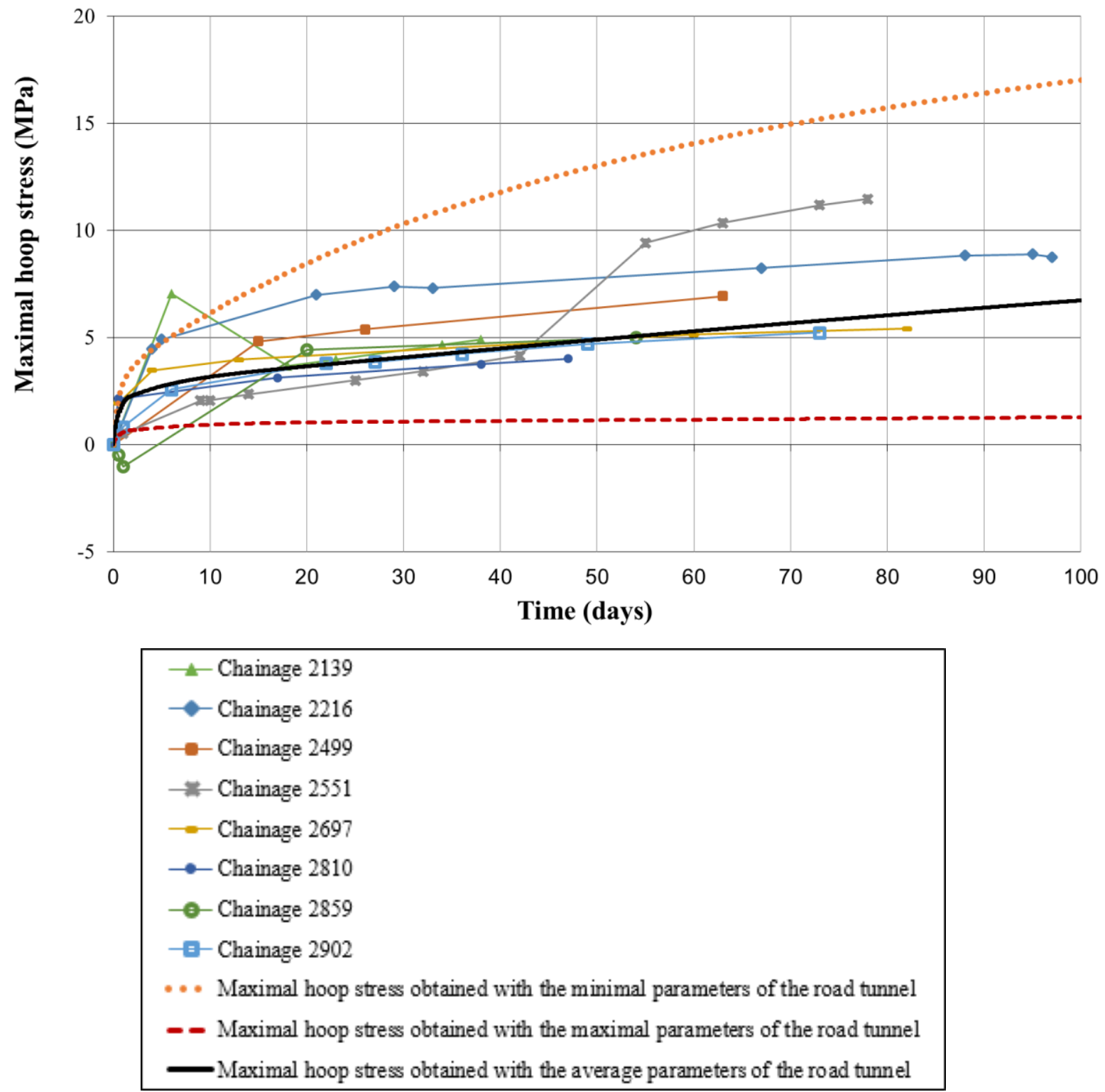

Fig23. Predicted envelope of maximal hoop stress in the safety gallery and retrieved maximal hoop stress from sections within zone A 


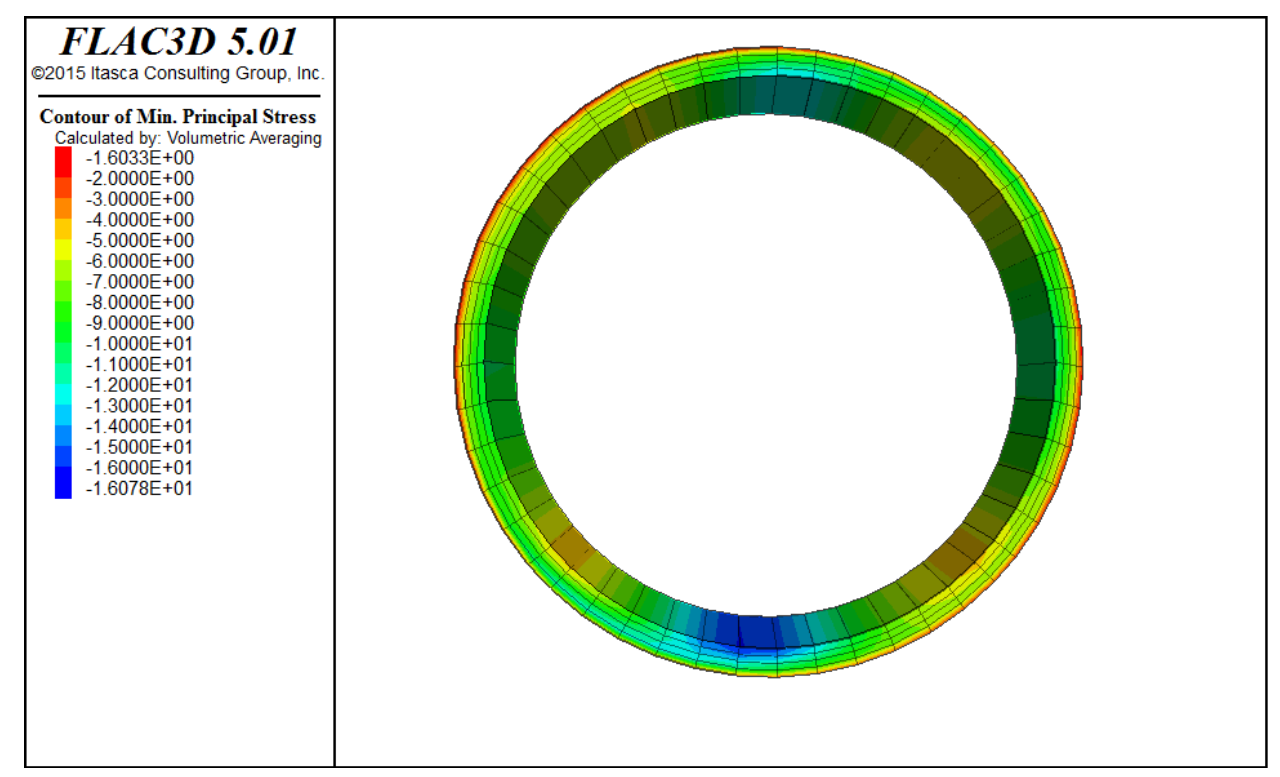

Fig24. Minimal principal stress (maximal compression) in the lining after 3 months (maximal constitutive parameters for the ground are assumed in the computation) 


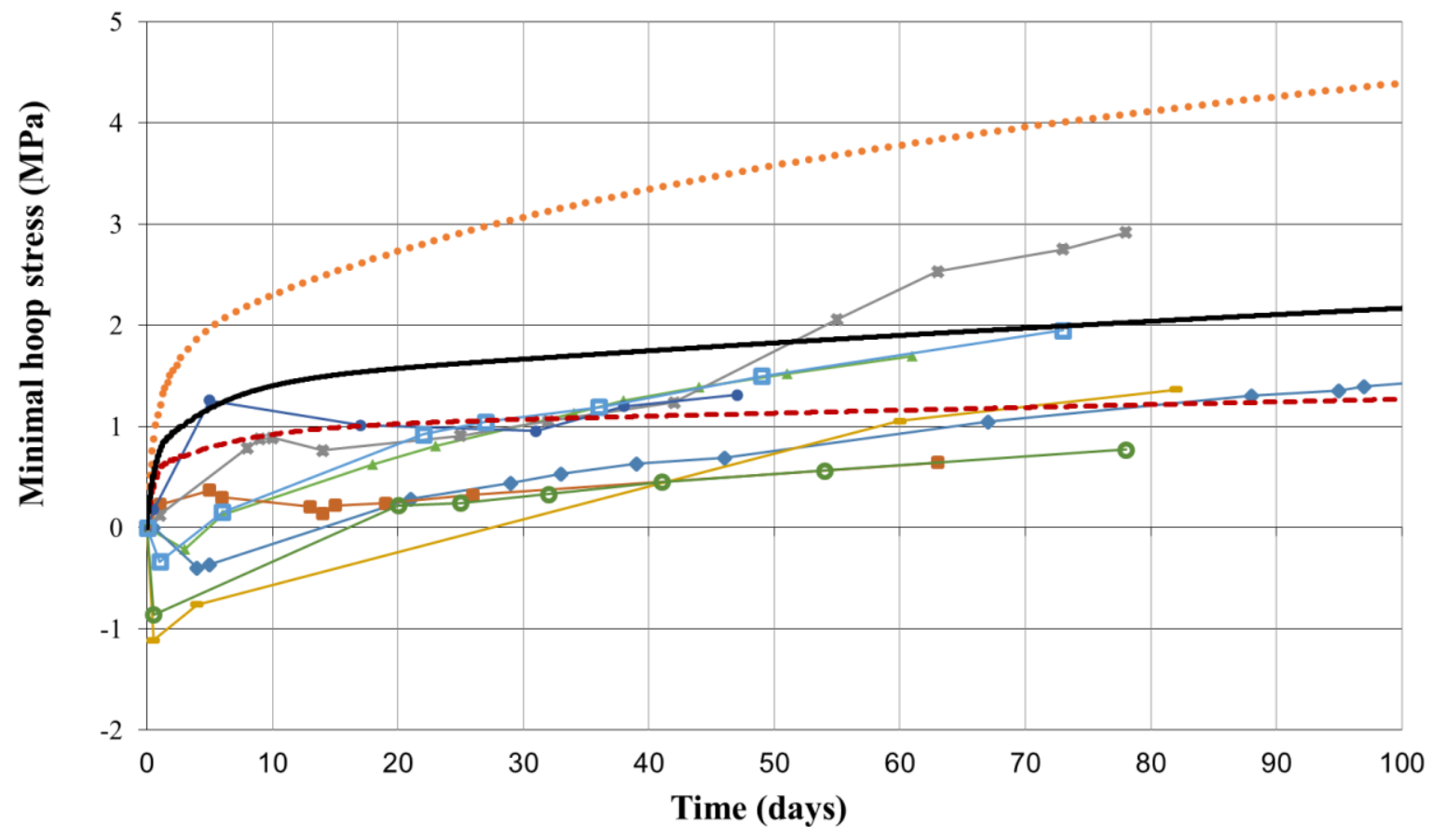

1

4

5

6

7

8

9

10

11

12

13

14

15

16

17

18

19

Fig25. Predicted envelope of minimal hoop stress in the safety gallery and retrieved minimal hoop stress from sections within zone A 


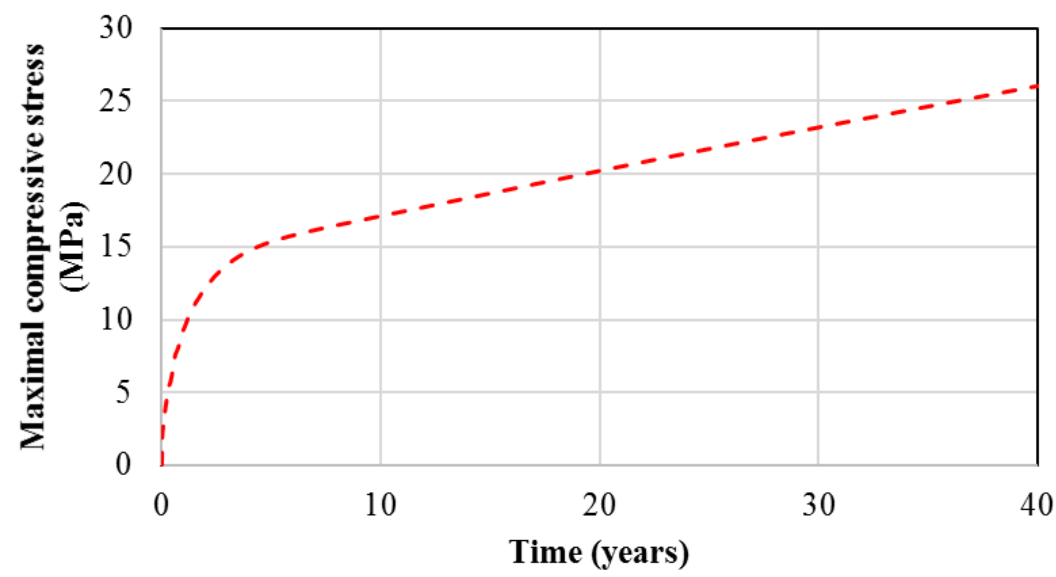

1
2 Fig26. Highest computed compressive stress as a function of time 